\title{
Downslope föhn winds over the Antarctic Peninsula and their effect on the Larsen ice shelves
}

\author{
D. P. Grosvenor ${ }^{1, *}$, J. C. King ${ }^{2}$, T. W. Choularton ${ }^{1}$, and T. Lachlan-Cope ${ }^{2}$ \\ ${ }^{1}$ University of Manchester, Centre for Atmospheric Science, SEAES, Manchester, UK \\ ${ }^{2}$ British Antarctic Survey, Cambridge, UK \\ *now at: School of Earth and Environment, University of Leeds, Leeds, UK \\ Correspondence to: D. P. Grosvenor (daniel.p.grosvenor@gmail.com)
}

Received: 3 January 2014 - Published in Atmos. Chem. Phys. Discuss.: 5 March 2014

Revised: 10 July 2014 - Accepted: 4 August 2014 - Published: 16 September 2014

\begin{abstract}
Mesoscale model simulations are presented of a westerly föhn event over the Antarctic Peninsula mountain ridge and onto the Larsen $\mathrm{C}$ ice shelf, just south of the recently collapsed Larsen B ice shelf. Aircraft observations showed the presence of föhn jets descending near the ice shelf surface with maximum wind speeds at $250-350 \mathrm{~m}$ in height. Surface flux measurements suggested that melting was occurring. Simulated profiles of wind speed, temperature and wind direction were very similar to the observations. However, the good match only occurred at a model time corresponding to $\sim 9 \mathrm{~h}$ before the aircraft observations were made since the model föhn jets died down after this. This was despite the fact that the model was nudged towards analysis for heights greater than $\sim 1.15 \mathrm{~km}$ above the surface.

Timing issues aside, the otherwise good comparison between the model and observations gave confidence that the model flow structure was similar to that in reality. Details of the model jet structure are explored and discussed and are found to have ramifications for the placement of automatic weather station (AWS) stations on the ice shelf in order to detect föhn flow. Cross sections of the flow are also examined and were found to compare well to the aircraft measurements. Gravity wave breaking above the mountain crest likely created a situation similar to hydraulic flow and allowed föhn flow and ice shelf surface warming to occur despite strong upwind blocking, which in previous studies of this region has generally not been considered. Our results therefore suggest that reduced upwind blocking, due to wind speed increases or stability decreases, might not result in an increased likelihood of föhn events over the Antarctic Peninsula, as previously suggested.
\end{abstract}

The surface energy budget of the model during the melting periods showed that the net downwelling short-wave surface flux was the largest contributor to the melting energy, indicating that the cloud clearing effect of föhn events is likely to be the most important factor for increased melting relative to non-föhn days. The results also indicate that the warmth of the föhn jets through sensible heat flux ("SH") may not be critical in causing melting beyond boundary layer stabilisation effects (which may help to prevent cloud cover and suppress loss of heat by convection) and are actually cancelled by latent heat flux ("LH") effects (snow ablation). It was found that ground heat flux ("GRD") was likely to be an important factor when considering the changing surface energy budget for the southern regions of the ice shelf as the climate warms.

\section{Introduction}

During the last 50-60 years near-surface temperatures over the Antarctic Peninsula (hereafter referred to as AP) region have increased more rapidly than anywhere else in the Southern Hemisphere, at several times the global average rate (Vaughan et al., 2003). One manned station on the west side of the Peninsula (Vernadsky, formerly Faraday) measured a mean near-surface warming of $2.94{ }^{\circ} \mathrm{C}$ between 1951 and 2004, significant at the $<1 \%$ level, compared to a global average of $0.52{ }^{\circ} \mathrm{C}$ over the same period (Marshall et al., 2006). Vaughan et al. (2003) estimated the mean warming trend for several of the Peninsula stations to be $3.7 \pm 1.6^{\circ} \mathrm{C}$ (century) ${ }^{-1}$ and suggested that current 


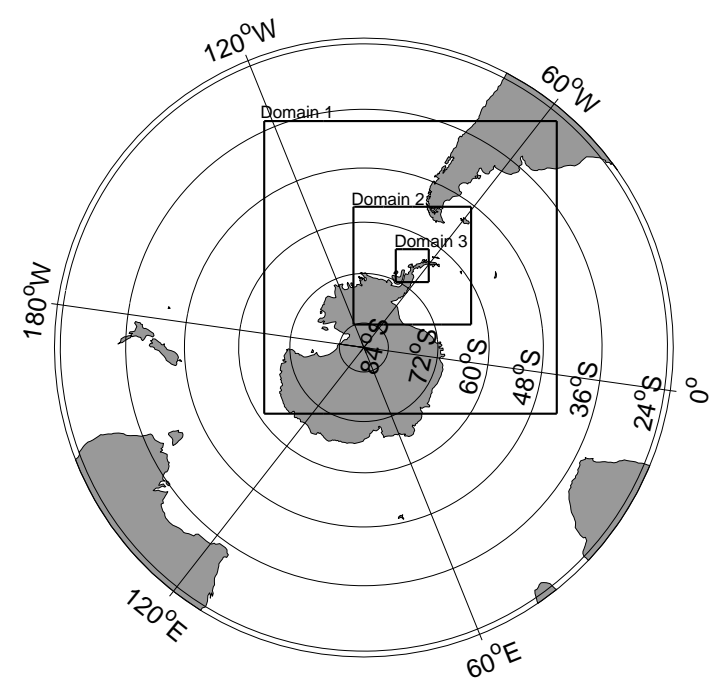

Figure 1. Locations of the WRF (Weather Research \& Forecasting) model domains used in this study. The square domains had sides of length 7470,3000 and $840 \mathrm{~km}$ with horizontal resolutions of $30,7.5$ and $1.875 \mathrm{~km}$ resolution for domains 1,2 and 3, respectively.

temperatures are unprecedented in the context of the past 1800 years for this region. It has recently been suggested, through a combination of infra-red satellite temperature measurements and station data, that the strong warming trend extends to the whole of West Antarctica, which is estimated to have exceeded $0.1^{\circ} \mathrm{C}(\text { decade })^{-1}$ over the past 50 years (Steig et al., 2009). In contrast, the same work and others (e.g. Turner et al., 2005) estimated a small and statistically insignificant trend for the larger area of East Antarctica over a similar period.

There is evidence that in the Antarctic Peninsula region, the seasonal pattern of local warming has varied with location. The Peninsula consists of a high, narrow mountain ridge that reaches over $2 \mathrm{~km}$ in altitude and runs for a length of around $1500 \mathrm{~km}$ (see Figs. 1, 3 and 4). Its length is orientated approximately from north to south and it is bounded to the south by the Antarctic continent. The high mountains provide a climatic barrier between the warmer oceanic air of the west and the cold continental air of the east where annual mean temperatures are $5-10{ }^{\circ} \mathrm{C}$ colder at comparable latitudes (King and Turner, 1997). There are few manned stations on the east side of the Peninsula, though, and they are all close to the northern tip of the Peninsula. Whether they reflect temperatures further south is therefore not certain. These stations have shown similar annual warming rates to those on the western side (Vaughan et al., 2003; Marshall et al., 2006). However, they recorded a much stronger warming trend in the seasons of Austral summer and autumn than those on the west side (Marshall et al., 2006). The summer trend in particular was highly statistically significant.

An indication of rising temperatures on the east side at more southerly latitudes came from the dramatic disintegra- tion of the Larsen B ice shelf in February to March 2002 when an area of $3200 \mathrm{~km}^{2}$ was lost (Scambos et al., 2004). The summer warming is especially important with respect to ice shelf disintegration since this is the season when the vast majority of surface melting on the ice shelves occurs. Crevasse propagation due to the weight of accumulated melt water is currently thought to have been the major factor in the 2002 break-up, as well as in the break-up of other ice shelves around the Peninsula (Scambos et al., 2000, 2004; van den Broeke, 2005).

Marshall et al. (2006) gave evidence that attributes the anomalous summer and autumn warming on the east side to changes in the Southern Hemisphere (SH) annular mode, or $\mathrm{SAM}$, which is the principle mode of variability in the $\mathrm{SH}$. A higher SAM index is associated with stronger westerly winds impacting on the Antarctic Peninsula. The SAM index increased between 1965 and 2000 with more statistically significant and much larger increases observed in the autumn and summer seasons. The increase in SAM index has been attributed to ozone loss (e.g. Thompson and Solomon, 2002; Gillett and Thompson, 2003), or greenhouse gas concentration increases (Kushner et al., 2001; Cai et al., 2003). Marshall et al. (2006) suggested that the stronger summer westerly winds associated with an increasing SAM index could lead to a higher frequency of penetration of warm air onto the east side of the Antarctic Peninsula, leading to enhanced warming in this region.

Warm and dry airflows down the lee slopes of a mountain are given various names around the world, the most commonly known being "föhn" (when it occurs in the Alps), "Chinook" (Rocky Mountains, North America) or "Zonda" (Argentine Andes). We use the term "föhn" in this paper. The warming on the downwind/lee side relative to a position on the upwind side at the same altitude occurs due to latent heat release on the upslope (western) side (if combined with precipitation losses) and/or adiabatic descent of air from upperlevels downwards towards the surface. Both of these mechanisms will also tend to make the downwind air drier than that at an equivalent altitude upstream.

Given the likelihood that such flows over the AP have increased in frequency over the past 50 years in response to a strengthening of the prevailing westerly winds, and the possibility of a connection with Larsen ice shelf break-up, knowledge of the details of these flows is important in order to understand the conditions in which they form, the degree of warming they are likely to provide to the east side, and the consequences of the flows for ice shelf melt rate and stability. However, little is known about these details in the context of the Antarctic Peninsula, except for the very recent results of Elvidge et al. (2014). In the latter some simulations of föhn flow and comparisons to aircraft observations for three different types of flow regime were presented following the OFCAP (Orographic Flows and the Climate of the Antarctic Peninsula) field campaign. These results are discussed further in Sects. 3.6.2 and 4.3.4. Our paper will focus on the 

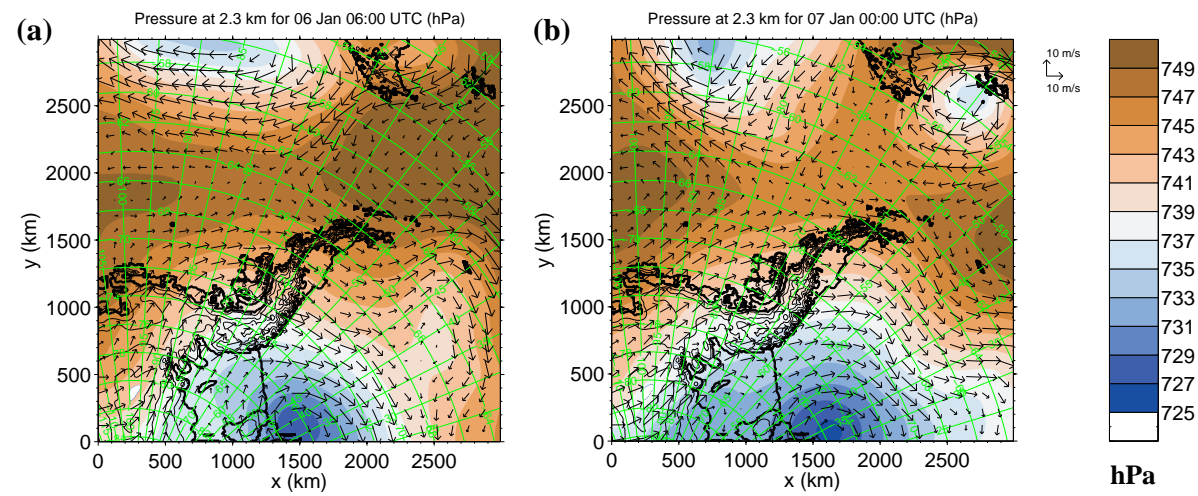

Figure 2. Pressure and wind vectors at $2.3 \mathrm{~km}$ a.s.1. for WRF domain 2 at (a) 06:00 UTC, 6 January and (b) 00:00 UTC, 7 January.
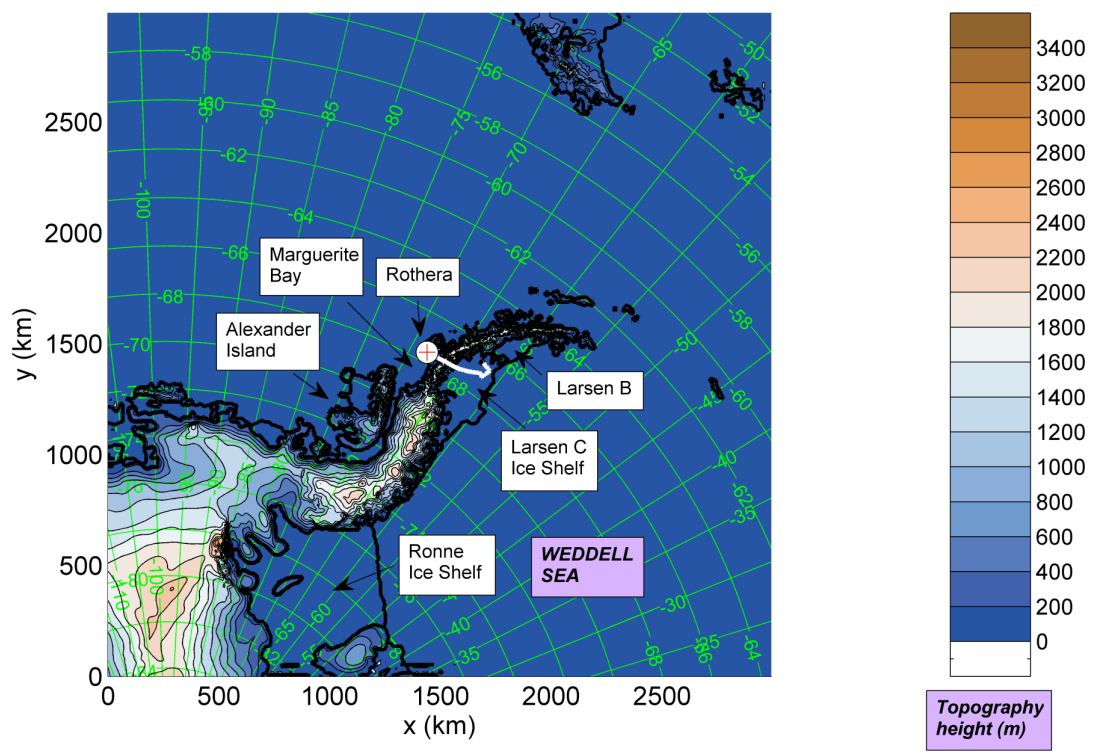

Figure 3. The area of the second WRF domain (see Fig. 1) showing the topography height (coloured contours) and various landmarks, including the Rothera BAS research base (white dot with red cross inside). The aircraft flight track is indicated by a white line.

simulation of a different föhn event over the Antarctic Peninsula, which was characterised by observations from an instrumented aircraft.

The breakdown of the sections of the paper is as follows: Sect. 2 describes the aircraft data used and the set-up for the simulation; results regarding the meteorology, structure and thermodynamics of the modelled jets and how they compare to observations are described in Sect. 3; Sect. 4 describes the surface energy balance results and simulated amount of surface ice melting; and Sect. 5 provides discussions and conclusions.

\section{Data and methods}

The focus of this paper will be a föhn event that occurred on the east side of the Antarctic Peninsula on 6 January 2006 when the airflow was from west to east. This event was ob- served by an instrumented aircraft and was simulated using a high-resolution regional atmospheric model. In this section we briefly describe the aircraft and the modelling system used.

\subsection{Aircraft observations}

Observations were made by an instrumented DHC6 Twin Otter aircraft operated by the British Antarctic Survey. The aircraft instrumentation is described by King et al. (2008). Briefly, the aircraft recorded basic meteorological variables (pressure, temperature, frost point temperature, wind speed and direction) at flight level. In addition, a remote measurement of surface temperature was available from a downwardpointing infrared thermometer and upwelling and downwelling long- and short-wave radiative fluxes were measured by aircraft-mounted pyrgeometers and solarimeters. 

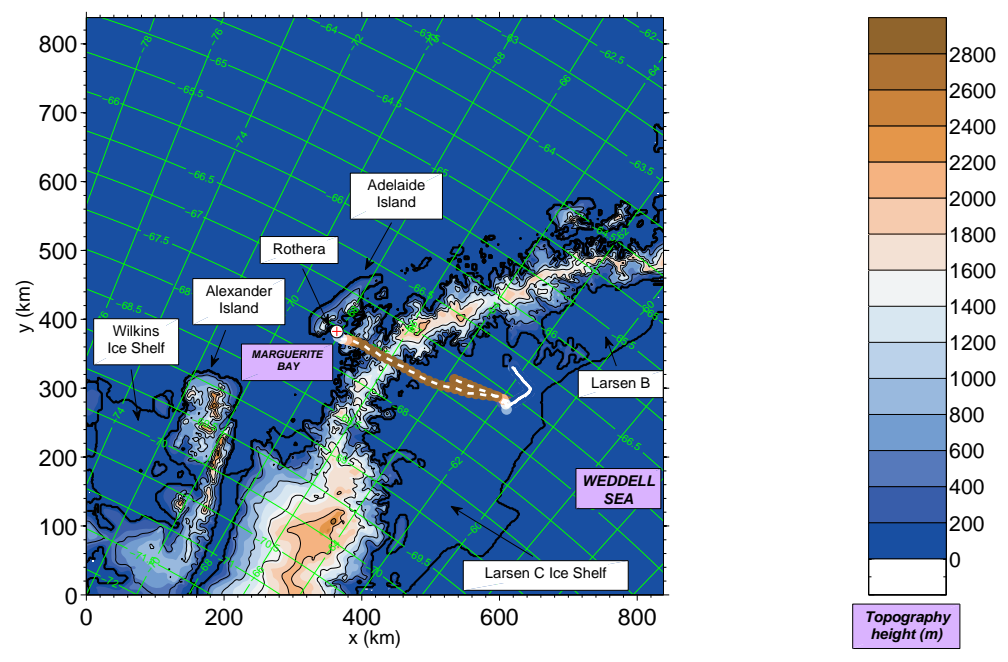

Figure 4. As for Fig. 3 except for the third WRF domain (see Fig. 1) and that here the black topography contours are every $500 \mathrm{~m}$. The aircraft flight track is indicated by the white dotted line surrounded by coloured circles, which show the aircraft altitude on the same colour scale as the topography.

Figure 4 shows the flight track of the aircraft with the aircraft altitude shown in colour. The aircraft took off from Rothera Research Station (see Fig. 4) at 19:20 UTC, 6 January and headed east. It traversed the Antarctic Peninsula ridge at $3000 \mathrm{~m}$ in altitude until the aircraft was $\sim 170 \mathrm{~km}$ downwind of the ridge crest. Then, at 20:15 UTC, the aircraft descended towards the surface of the Larsen $\mathrm{C}$ ice shelf over a horizontal distance of $\sim 10 \mathrm{~km}$ where it performed some low-level flight legs, which will be discussed later (Appendix A). At 22:00 UTC it made another ascent within $\sim 10 \mathrm{~km}$ of the descent profile and returned back over the ridge along a similar path. The reader is also referred to King et al. (2008) for further information on this case study.

\subsection{WRF modelling introduction}

The model used is a version of the WRF (Weather Research \& Forecasting) mesoscale model (Skamarock and Klemp, 2008) that has been specially modified for use in polar regions by researchers at the Bryd Polar Research Center (Hines and Bromwich, 2008; Bromwich et al., 2009; Wilson et al., 2011; Hines et al., 2011) through improvements in the representation of the polar surface; the WRF parameterisation options that are now listed were selected according to these studies and the reader is referred there for further details and for justifications for these choices: the rapid radiative transfer model (RRTM) was selected for long-wave radiation ("LW") and the Goddard scheme for short-wave radiation ("SW"); the Mellor-Yamada-Janjić Turbulent Kinetic Energy (TKE) scheme was used for the boundary layer option in conjunction with the Janjić Eta scheme for the surface layer (Janjić, 2002), which is based on Monin-Obukhov similarity theory, but with moisture and thermal roughness lengths that scale with those for momentum as a function of the molecular viscosity for momentum and the friction velocity, following Zilitinkevich (1995); for the land surface model, the four-layer unified Noah scheme was selected. As described in Hines and Bromwich (2008), the latter was modified to deal with deep snowpack and the density, heat capacity and heat conductivity of the snowpack are based upon observations of Antarctic snow firn.

Three grid nests were used of horizontal resolution 30 , 7.5 and $1.875 \mathrm{~km}$ for the outer, middle and inner nests, respectively. The inner nest is $840 \mathrm{~km} \times 840 \mathrm{~km}$, centred on the area where the aircraft flew. Figure 1 shows the nest positions and sizes relative to the Peninsula. The two lowest resolution nests used the Kain-Fritsch convection scheme, which parameterises deep and shallow convection, whereas the inner nest did not use a convection parameterisation. There were 81 vertical levels specified and vertical resolution generally decreased with height. On average, the vertical resolution started at $\sim 27 \mathrm{~m}$ near the surface and was relaxed to 240 $250 \mathrm{~m}$ by the time the mid-troposphere was reached, and then remained at this value throughout most of the rest of the troposphere.

The model was initialised with and received lateral boundary information from ECMWF operational analysis data, which for the period in question was available at $0.5^{\circ} \times 0.5^{\circ}$ horizontal resolution with 61 vertical levels. The simulation was started at 00:00 UTC, 5 January 2006 and ran until 00:00 UTC, 8 January 2006. It was decided to perform nudging on all model nests so that the model fields of horizontal wind, temperature and vapour mixing ratio are constantly being moved towards the above mentioned ECMWF analysis fields. This was done since otherwise it was found that the fields drifted away from the analysis, most likely as a result of the combination of rapidly changing analysis 
fields, the large domain sizes and the fairly long time period of the simulation. The nudging was only applied above the 10th vertical model level, which corresponds to a height of $\sim 1.15 \mathrm{~km}$ above the terrain. The relaxation timescale was $t_{\text {relax }}=55.6 \mathrm{~min}$. If there are no other forcings, then a model variable, $q(t)$, would change due to the nudging according to the following:

$q(t)=q(0)+\left(1-e^{-t / t_{\text {relax }}}\right)\left(q_{\text {target }}-q(0)\right)$.

Here, $t$ is the time in minutes since the start of the relaxation and $q_{\text {target }}$ is the target analysis value.

\section{The thermodynamics and meteorology of the föhn flow}

\subsection{The synoptic situation}

The general synoptic situation during the period of the simulation was dominated by circumpolar flow around Antarctica, which carried a succession of low-pressure systems around the pole. At the start of the simulation (05:00 UTC, 5 January), two such systems were located to the west and east of the southern tip of S America with surface low-pressure centres at approximately $52.5^{\circ} \mathrm{S}$ in latitude and at longitudes of 100 and $40^{\circ} \mathrm{W}$, respectively. As the systems progressed eastwards, the edge of the westernmost system started to impact onto the west coast of S America by around 12:00 UTC, 5 January and by 06:00 UTC, 6 January part of the system was located over the eastern coast of S America. The surface pressure field of the system had split into two almost equally sized low-pressure systems by 09:00 UTC, 7 January on either side of S America. By the end of the simulation the bulk of the system was on the east side and had travelled southwards slightly, lying just to the NE of the tip of the Antarctic Peninsula (centred at $57^{\circ} \mathrm{S}, 50^{\circ} \mathrm{W}$ ).

Figure 2a shows the WRF pressure field at a height of $2.3 \mathrm{~km}$ at 06:00 UTC on the morning of the aircraft flight on 6 January. This is very similar to the ECMWF analysis pressure field at the same height. This height is just above the maximum height of the ridge and therefore the wind at this level will likely be important in determining the cross Peninsula flow. The western low-pressure system can be seen to the north-west of the AP. A high pressure ridge to the west of the Peninsula extended east and north beyond the Peninsula tip. It separated a large low-pressure system centred south-east of the Peninsula from two low-pressure systems off the west and east coasts of the southern tip of S America that were described above. At the location of the flight (see Figs. 3 and 4), the western branch of the clockwise circulation of the lowpressure system to the south-east is impacting onto the west side of the Peninsula with flow that is almost perpendicular across the ridge. The analysis winds over the ridge are approximately southwesterly $\left(240-245^{\circ}\right)$ and have speeds that vary between 5 and $10 \mathrm{~m} \mathrm{~s}^{-1}$ between the ridge top height and $3000 \mathrm{~m}$. This period is associated with föhn flow that will be described in more detail later.

Figure 2b shows the situation at 00:00 UTC, 7 January. The splitting of the low-pressure system over S America can be seen in this figure. As this system moved to the east side of S America it started to affect the low-pressure system to the SE of the AP causing it to widen and move slightly eastwards. At this time the winds associated with the latter system at the western side of the AP are more southerly and no longer impact the AP in a direction perpendicular to the ridge. The overall change in direction is around $45^{\circ}$. In addition, the winds there also weaken after 00:00 UTC, 7 January. After 15:00 UTC, 6 January, the föhn flow started to die down and the changes in the wind direction and speed just described are likely the main reasons for this.

Further details about the properties of the upstream flow (wind speed, Froude number, stability profiles, etc.), its evolution and its relationship to the föhn flow are described in Sect. 3.6.

\subsection{Aircraft observations of the föhn jet}

The flight track of the aircraft was described in Sect. 2.1; we now discuss the observations that were made during the flight. During the initial ascent (close to Rothera) the measured wind direction between $\sim 1700$ and $3000 \mathrm{~m}$ varied from $\sim 225$ to $250^{\circ}$ and the wind speed was between 8.5 and $12 \mathrm{~m} \mathrm{~s}^{-1}$ (not shown). Thus, the analysis winds (Fig. 2) were in a similar direction to, but were a little weaker than those measured. Wind profile data was not available below $1700 \mathrm{~m}$ on the ascent due to instrument malfunction. As the aircraft crossed the Peninsula, heading from west to east, the wind direction remained westerly to southwesterly revealing that cross ridge winds prevailed at this time.

When the aircraft descended towards the Larsen $\mathrm{C}$ ice shelf a strong low-level wind jet was observed. This is shown in Fig. 5a labelled as "Aircraft descent". Wind speed peaked at $15 \mathrm{~m} \mathrm{~s}^{-1} 250 \mathrm{~m}$ above the surface, while the wind direction changed quite sharply from being approximately southwesterly to westerly $\left(245-265^{\circ}\right)$ at $800-3000 \mathrm{~m}$ towards a southerly direction at the height of the jet maximum (Fig. 5b). Below, the jet wind direction sharply changed back to become almost westerly again close to the surface.

Warm air temperatures (Fig. 5c) were observed at around the same height as the jet wind speed maximum with a maximum of $4.6^{\circ} \mathrm{C}$ at $283 \mathrm{~m}$ above the surface. The presence of this warm air caused a strong temperature inversion above the ice surface. The surface itself remained close to $0^{\circ} \mathrm{C}$, as confirmed by the surface infrared aircraft measurements (King et al., 2008). King et al. (2008) also showed that the downwind air had a considerably higher potential and equivalent potential temperature and was drier than that at equivalent altitudes on the upwind side. This indicates either adiabatic warming due to the descent of dry air that originated from above the mountain, or diabatic warming of air that came 
(a)

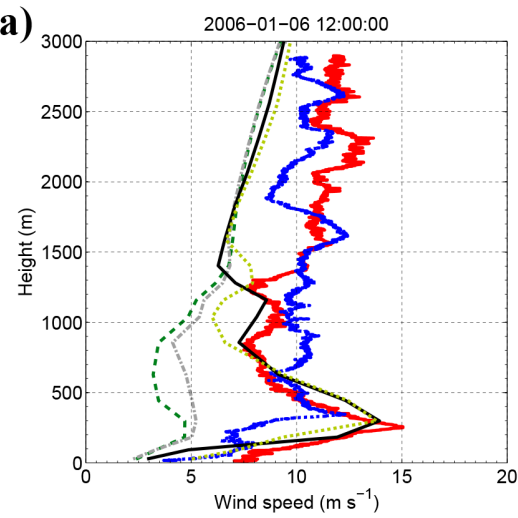

(c)

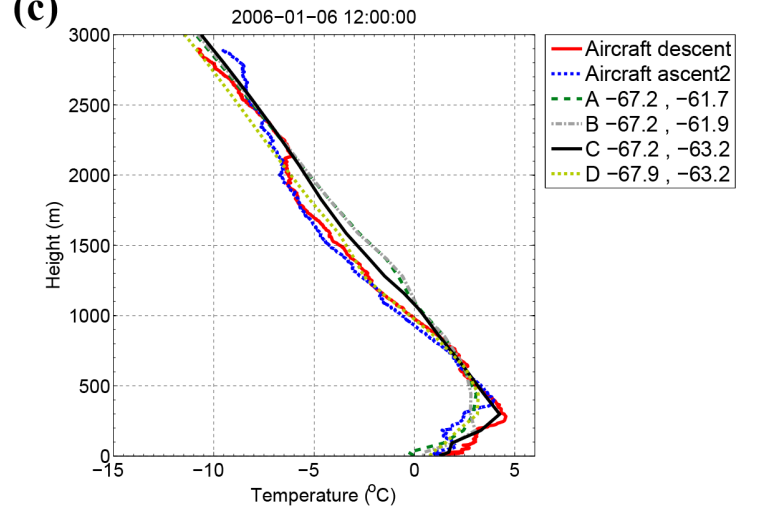

(b)

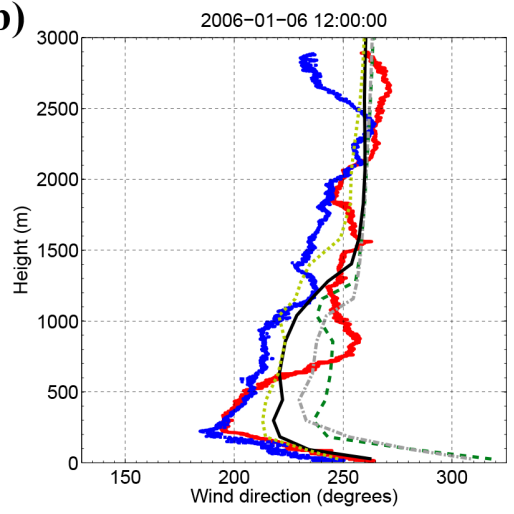

Figure 5. Profiles from the aircraft observations and from domain 3 of the WRF model. Aircraft profiles were taken during the descent down to the ice shelf between 20:14 and 20:24 UTC, 6 January and during the ascent away from the ice shelf before the journey back to base from 22:00 to 22:09 UTC. Model profiles are for 12:00 UTC, 6 January from various locations (labeled with letters in the legend). See Fig. 8b for a map of the locations of these profiles. The profiles are (a) wind speed, (b) wind direction and (c) temperature.

from below the mountain on the upwind side and experienced latent heat warming due to ice or liquid formation and drying by precipitation loss.

Figure 7 shows MODIS images over the peninsula ridge from 13:00 UTC, 6 January. Figure 7b shows that most of the Larsen C ice shelf was relatively cloud free since the ice surface shows up as red, whereas cloud shows as white. There is cloud upwind; however, Fig. 7a demonstrates that this is quite thin. A linear band of thicker cloud can be seen orientated along the ridge crest that is associated with the mountain wave, although there is a gap in this cloud just north of Adelaide Island and Rothera. These observations suggest that latent heating through condensation followed by precipitation removal is not a big contributor to the downwind warming in this case.

On the ascent before the return back to base at 22:00 UTC the wind jet was again observed (Fig. 5a, labelled as "Aircraft ascent2") but with a lower maximum speed of $12.4 \mathrm{~m} \mathrm{~s}^{-1}$ and the height of this maximum had risen from 250 to $345 \mathrm{~m}$ above the ice shelf surface. The wind direction at the height of the maximum was southerly, as was the case on the descent. However, above here (between 600 and $2000 \mathrm{~m}$ ) the wind was closer to westerly on the descent, but by the time of the ascent had rotated towards a more southerly direction (Fig. 5b).

Thus, the observational evidence suggests that a cross ridge flow generated a föhn event that produced strong wind jets and temperatures higher than $0^{\circ} \mathrm{C}$ above the ice shelf surface to the east of the mountain barrier. Such temperatures could promote melting of the ice surface; the issue of ice melting, including results on the amount of melting at different locations on the ice shelf as predicted by the WRF model and the likely contributions from different processes are discussed later in Sect. 4.

\subsection{Description of the simulated föhn jets}

Figures 6 and 8 show plan views of the horizontal wind fields on the fourth vertical model level for the inner domain of the simulation at various times. The actual height represented by this model level varies with position in the domain depending on the terrain height and pressure level distortion. However, over the ice shelf the model level height is approximately uniform at $293 \mathrm{~m}$ above the surface. This height is close to that at which the maximum wind speed was observed during the initial aircraft descent over the ice shelf $(250 \mathrm{~m}$ above the ice shelf), and also during the final ascent ( $350 \mathrm{~m}$ above the ice 


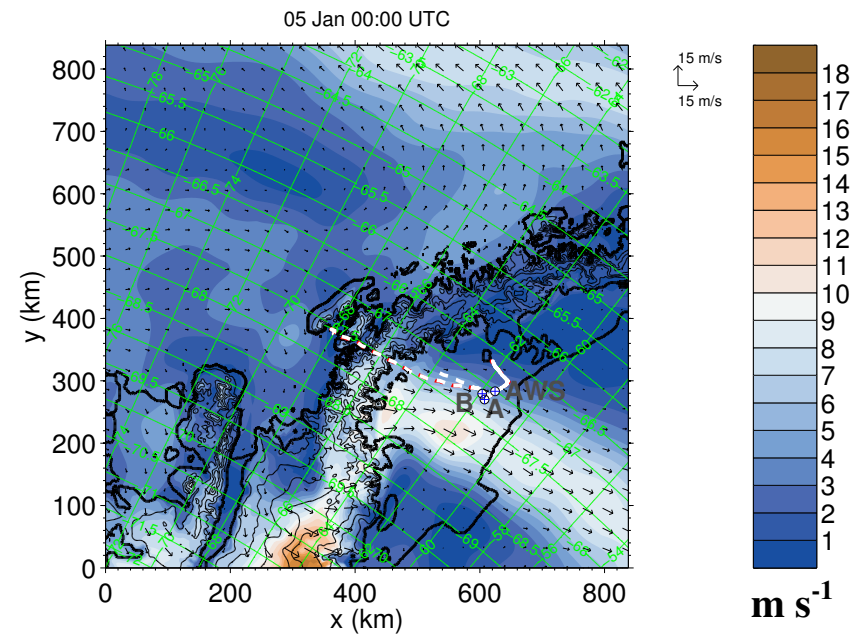

Figure 6. Domain 3 horizontal wind speed and wind vectors on the fourth vertical model level at the beginning of the simulation at 00:00 UTC, 5 January. This therefore represents the initial wind field as interpolated from the ECWMF analysis. Marked on here is the flight path of the aircraft (white dotted line). The marked location, $\mathrm{A}$, is where the maximum wind speed was measured during the aircraft's descent onto the ice shelf. Location B is the position of the maximum wind speed during the ascent from the ice shelf before flying back over the peninsula. Also marked is the location of the automatic weather station (AWS).

shelf; see Fig. 5). The former was observed at 20:23 UTC at the location marked as point A in Figs. 6 and 8 and the latter at 22:01 UTC only $10 \mathrm{~km}$ from the descent maxima (labeled point B).

The initial conditions for the WRF run (Fig. 6), which were taken from the European Centre for Medium-Range Weather Forecasts (ECMWF) analysis at 00:00 UTC, 5 January, show moderate winds on this model level of up to $10.9 \mathrm{~m} \mathrm{~s}^{-1}$ in the form of a fairly wide jet that covers approximately the same latitude range as the gap in the topography between the high terrain of Alexander Island and Adelaide Island. The jet starts at the eastern foot of the Peninsula mountains and continues past the edge of the Larsen $\mathrm{C}$ ice shelf and beyond the edge of domain 3 . This suggests that the ECMWF analysis has some ability to resolve the föhn flow in this region and that the föhn may have been active before 00:00 UTC, 5 January. However, the resolution of the ECMWF analysis model is likely to be too coarse to resolve a lot of the details of the topography and the flow.

As the high-resolution WRF model began to spin up and evolve it started to resolve this single large jet into smaller more intense jets at various locations along the eastern foot of the mountains (not shown). However, these jets were shortlived and by 21:00 UTC, 5 January the winds were relatively calm over the ice shelf. At this time, though, low-level winds that were directed towards the Peninsula were starting to build up around the base of the northern part of Alexander
Island on the upwind side of the flow. In addition, the winds immediately above the ridge of the Peninsula were also intensifying. By 03:00 UTC, 6 January, jets again started to appear at several locations over the Larsen $\mathrm{C}$ ice shelf at the eastern foot of the ridge. At 09:00 UTC (Fig. 8a), three main jets have formed, the edges of which have progressed eastwards by around $100 \mathrm{~km}$. These are marked as jets 1,2 and 3 and will be referred to as such from now on. The wind speeds in these jets at this height reached up to $18 \mathrm{~m} \mathrm{~s}^{-1}$.

After this time the jets started to move northwards whilst low-level southerly winds start to develop along the east side of the Peninsula at the southern end of the Larsen C ice shelf (see Fig. 8b). This northward progression of the jets caused the two most northern jets, jets 1 and 2, to merge together by 12:00 UTC, 6 January (Fig. 8b). By this time the jets reached almost as far east as the locations where the aircraft observed the strong jet on the descent and ascent at 20:23 and 22:01 UTC (labeled A and B, respectively, in Fig. 8).

\subsubsection{The influence of the Coriolis effect}

Given the high latitude of this location a fairly strong Coriolis effect is expected that would turn winds to the left. Since the modelled jets were fairly strong it seems feasible that their movement northwards could have been due to this effect. To examine this possibility, the surface pressure field and the wind vectors at the fourth model level at 15:00 UTC are shown in Fig. 9a. At this time there is a small lowpressure system centred near the eastern edge of the ice shelf $(x=578, y=216 \mathrm{~km})$ that has a fairly weak cyclonic circulation associated with it. It is clear that at the locations on the northern part of the ice shelf, where the jet speed is the greatest, the jets are turning northwards (to the left in the sense of the jet direction) across the direction of the isobars, suggesting that the influence of the Coriolis effect is dominating there. Using the pressure gradient between $x=469 \mathrm{~km}, y=159 \mathrm{~km}$ and the centre of the low-pressure system, the pressure gradient acceleration is calculated to be $6 \times 10^{-4} \mathrm{~m} \mathrm{~s}^{-2}$, whereas the Coriolis acceleration calculated using the wind speed of the southernmost jet $\left(14 \mathrm{~m} \mathrm{~s}^{-1}\right.$, jet 3) at $x=450, y=230 \mathrm{~km}$ is $1.9 \times 10^{-3} \mathrm{~m} \mathrm{~s}^{-2}$, which is over three times larger than the pressure gradient acceleration.

From 15:00 UTC onwards, the wind speeds of most of the modelled jets started to reduce in intensity. The surface pressure field evolved such that the low-pressure system moves east and by 21:00 UTC, 6 January its centre was located beyond the edge of the ice shelf (Fig. 9b). The associated pressure gradient has increased slightly and the winds in the southern half of the ice shelf are now stronger and directed from the south across most of that half of the ice shelf. The remnants of the jets continue to move northwards, which is probably due to the influence of the southerly wind driven by the pressure gradient, since at this point the Coriolis effect is likely secondary over most regions. For example, at the location of jet 3 used above $(x=450, y=230 \mathrm{~km})$, the 


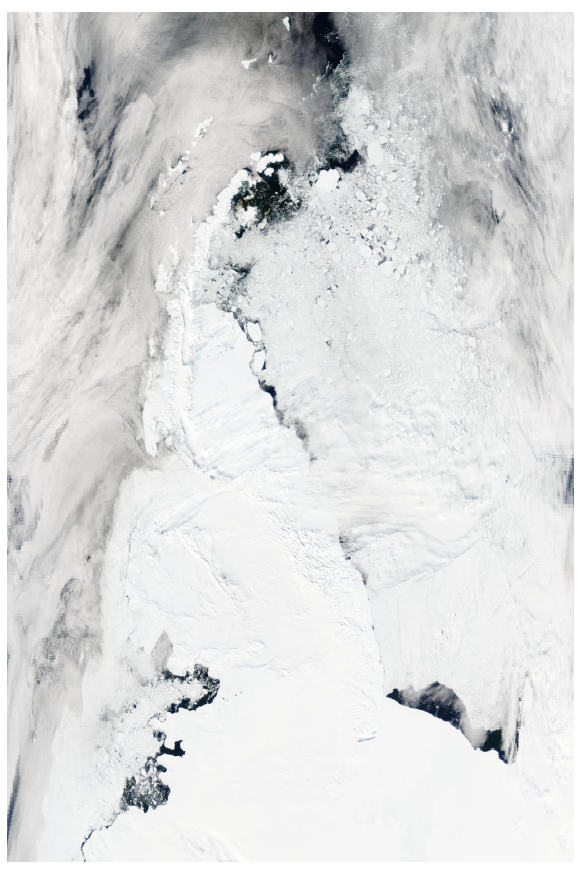

(a) 1-4-3 (visible) image

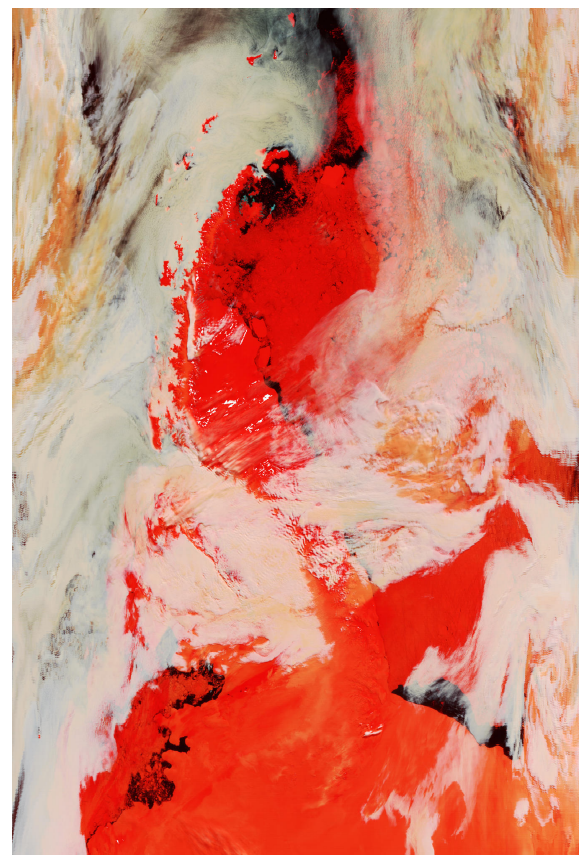

(b) 3-6-7 image

Figure 7. MODIS images over the Antarctic Peninsula region from 13:00 UTC, 6 January. (a) shows the visible image (bands 1, 4 and 3 used for red (R), green (G) and blue (B), respectively). (b) shows a false colour image using, respectively, bands 3, 6 and 7 for RGB. In (b) ice covered land shows up as red, whereas cloud shows up as white. The image is orientated approximately with north at the top and south at the bottom. The outline of the ice shelf, the ice covered land and sea ice to the east of the ice shelf can be discerned in (a) - see Fig. 4 to aid identification. (b) demonstrates that most of the Larsen C ice shelf was relatively cloud free. (a) shows that the cloud upwind (west) of the ridge is quite thin, whereas much thicker cloud is present along the ridge crest (except in the central portion of the ridge just north of Adelaide Island). Images were taken from http://lance-modis.eosdis.nasa.gov/cgi-bin/imagery/single.cgi?image=crefl1_ 143.A2006006130000-2006006130459.1km.jpg

wind speed has dropped to $2.8 \mathrm{~m} \mathrm{~s}^{-1}$ giving a Coriolis acceleration of $4 \times 10^{-4} \mathrm{~m} \mathrm{~s}^{-2}$. The pressure gradient acceleration calculated between $x=516, y=219 \mathrm{~km}$ and $x=638$, $y=212 \mathrm{~km}$ is now $6 \times 10^{-4} \mathrm{~m} \mathrm{~s}^{-2}$ and so is around $50 \%$ larger than the Coriolis acceleration.

\subsection{Model comparison to the observations}

\subsubsection{Wind speed}

The model output time of 21:00 UTC, 6 January is the closest available time to that of the aircraft observations of the strong wind jets at 20:23 and 22:01 UTC. At similar heights, the maximum wind speeds of the simulated flow in the region of the maximum observed jet speed are around $9.3 \mathrm{~m} \mathrm{~s}^{-1}$ (Fig. 8d). The simulated jets extend further east than where the observations were made showing that they penetrate at least as far across the ice shelf as the real föhn flow. However, the jet intensities are weaker than the observed jet winds, which had maxima of 12.4 and $15 \mathrm{~m} \mathrm{~s}^{-1}$ for the descent and ascent, respectively. Profiles through the centres (locations of the maximum wind speed) of the simulated jets (not shown) confirm that the modelled jet wind speeds are lower than those observed at this time throughout the boundary layer. The heights of the wind speed maxima in the jet profiles do agree well with the observed height, though.

Better agreement is obtained if the observed profiles (measurements between 20:00 and 22:00 UTC) are compared with modelled profiles at 12:00 UTC. At the model time of 12:00 UTC, the modelled föhn jets have not yet started to die down and jet 1 has just reached near to the regions where the real jets were observed. Profiles at this time are shown in Fig. 5 for various locations, which are marked in Fig. 8b. Location $\mathrm{C}$ is near the centre of the combination of modelled jets 1 and 2, which at this time is $\sim 55 \mathrm{~km}$ away from where the observations were made. Location $\mathrm{D}$ is at the centre of jet 3, which is further from the observation region at this time ( $\sim 100 \mathrm{~km}$ away). Below $\sim 1400 \mathrm{~m}$, the wind profiles at both locations are very similar to those observed on the aircraft descent with maxima of $\sim 14 \mathrm{~m} \mathrm{~s}^{-1}$ located at the same height as the observed maximum. However, since at 12:00 UTC the modelled jets do not reach as far east as the location where the aircraft observations were taken, this suggests some spatial offset to the jet locations compared to reality; model profiles $\mathrm{A}$ and $\mathrm{B}$ taken at the aircraft location 

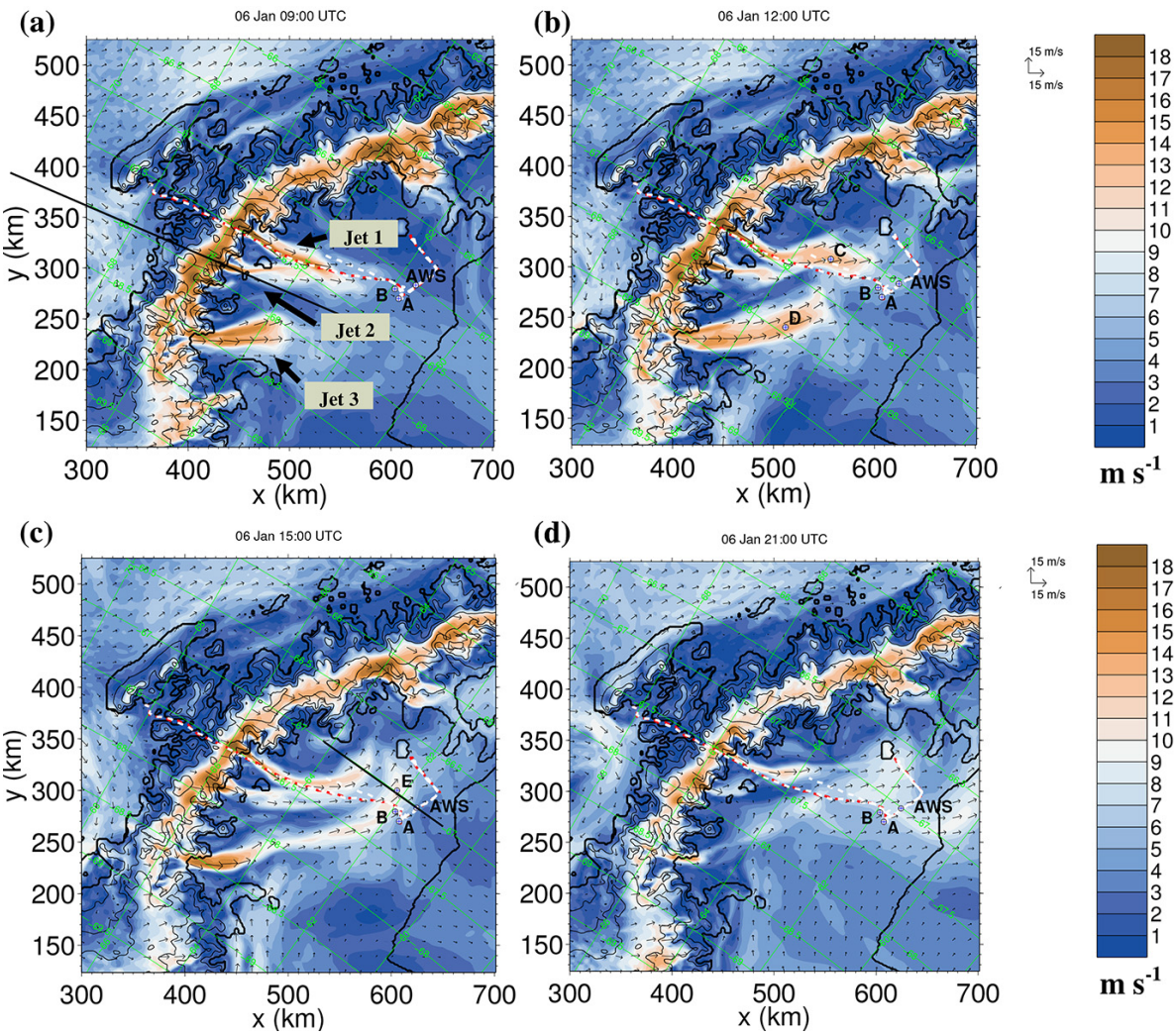

Figure 8. As for Fig. 6 except in close up view over the ice shelf and at different times on 6 January: 09:00 UTC (a), 12:00 UTC (b), 15:00 UTC (c) and 21:00 UTC (d). Also marked are the locations of various other points where the model profiles in Figs. 5 and 10 have been taken. The black straight line in (a) is the line over which the cross sections in Fig 15 were taken, and the line in (c) is that for the cross section in Fig 13.
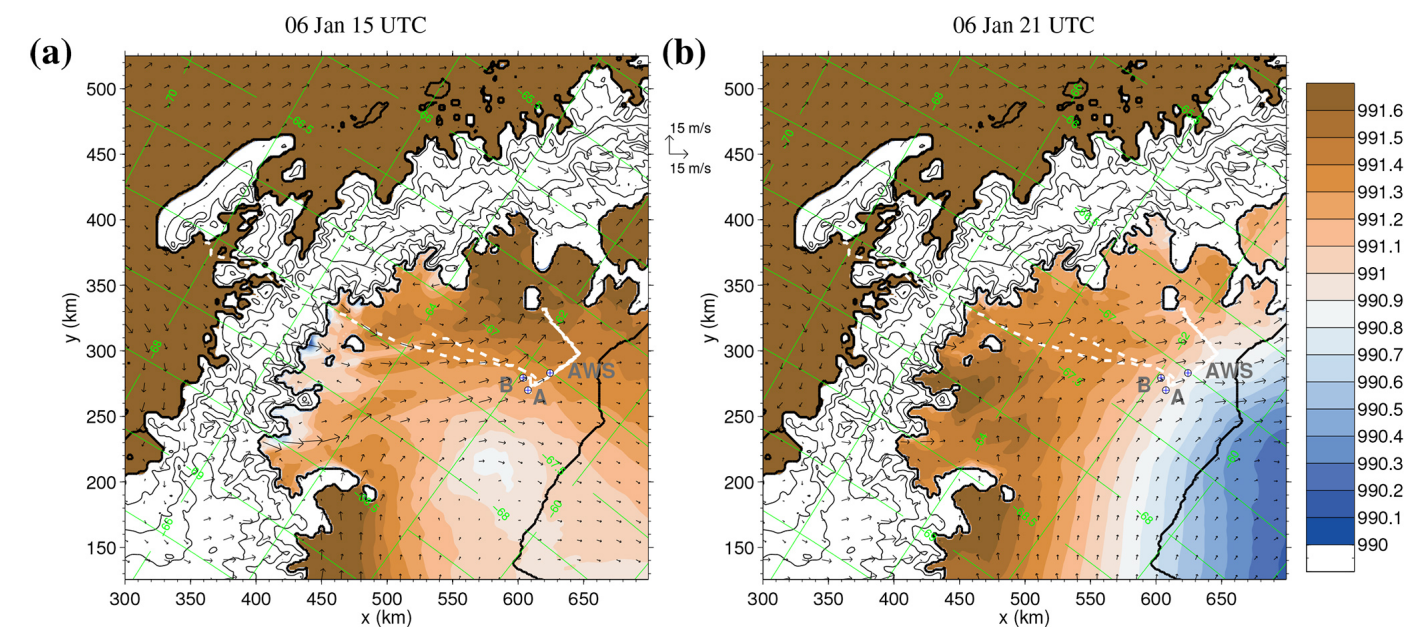

Figure 9. Surface pressure (colour contours; hPa) with wind vectors for the fourth model level at 15:00 UTC (a) and 21:00 UTC (b) 6 January.

show much lower wind speeds than those measured by the aircraft (Fig. 5a).

The wind speeds observed in the jet during the aircraft ascent at 22:01 UTC were weaker than those during the descent at 20:23 UTC up to an altitude of $\sim 400 \mathrm{~m}$, suggesting that the real jet reduced in intensity. In the model the jet was dying down in intensity after 12:00 UTC, 6 January, which indicates that a similar reduction in jet intensity occurred, except at an earlier time than in reality. 
(a)

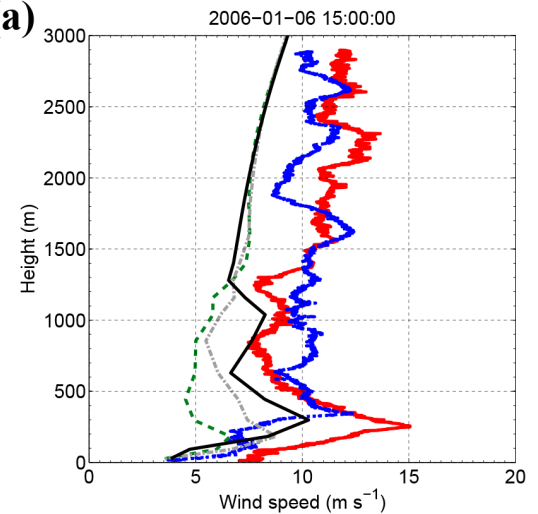

(b)

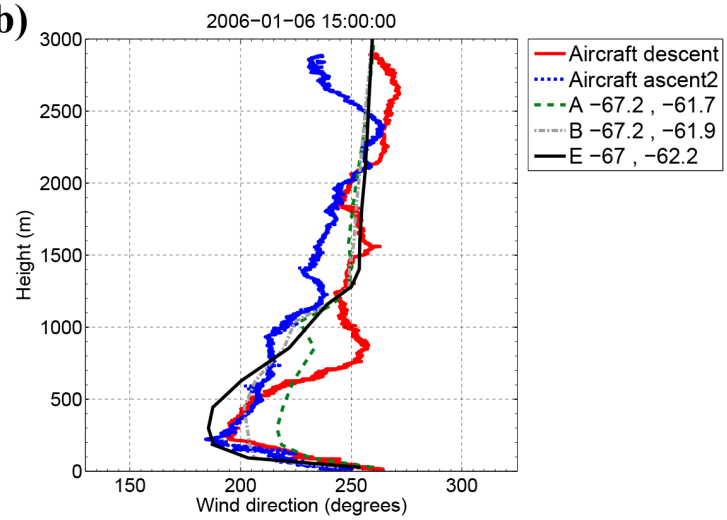

Figure 10. As for Fig. 5 except for at 15:00 UTC, 6 January and for wind speed (a) and direction (b) only. See Fig. 8c for a map of the locations of these profiles.

(a)

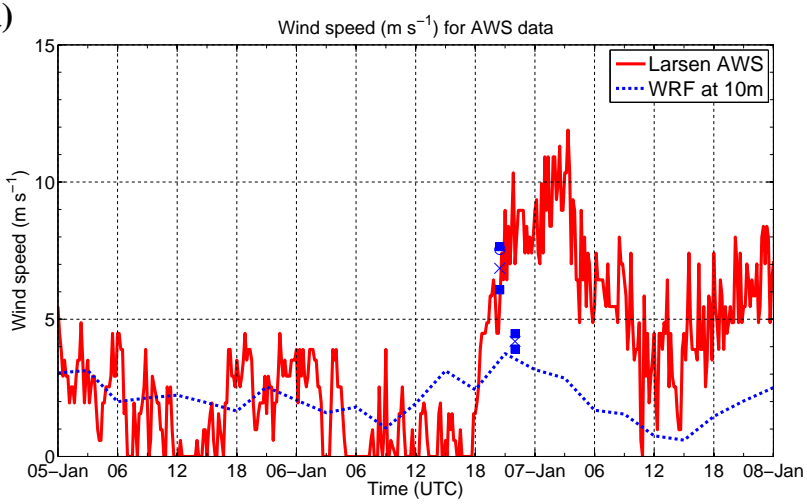

(b)

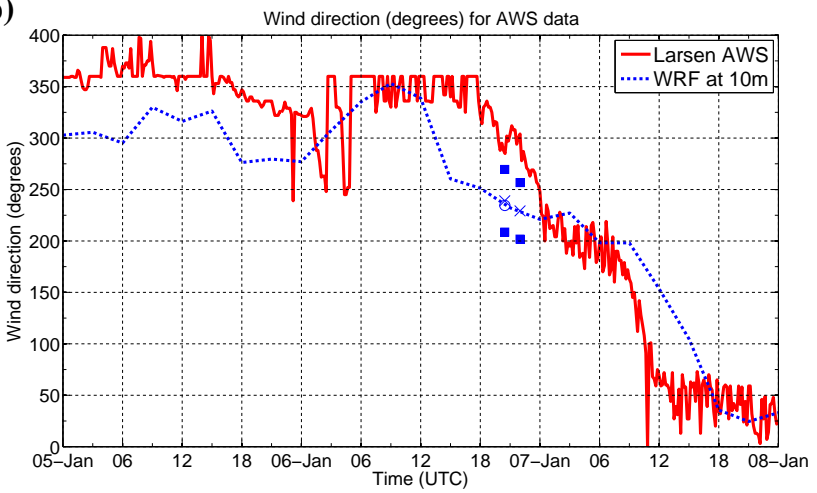

Figure 11. Time series from the Larsen C AWS along with the modelled values at the AWS location in domain 3; (a) $10 \mathrm{~m}$ wind speed $(S)$ and $(\mathbf{b}) 10 \mathrm{~m}$ wind direction $(\phi)$. Also marked are details of aircraft observations made during the A-L1 leg at $15 \mathrm{~m}$ altitude. For $S$ the mean values are shown by the blue cross and the filled squares denote $\pm 1 \sigma$. For $\phi$ the squares denote the full range of the wind direction during the leg and the cross shows the midpoint of the range. The circles show the observed value when the aircraft was directly above the AWS location. The same is marked for the later descent towards the ice shelf just before the final ascent from the region.

\subsubsection{Wind direction}

Figure $5 \mathrm{~b}$ shows the wind direction at the same model time (12:00 UTC) and locations as in the previous section. There is generally a very reasonable match between the modelled and observed wind direction profiles at all altitudes. The observed wind direction changes from westerly to southerly between the ground and the height of the jet wind speed maximum at $\sim 250-350 \mathrm{~m}$. The two model profiles at the centres of the strong jets (locations $\mathrm{C}$ and $\mathrm{D}$ ) exhibit a similar rotation in wind direction over the same height range, although the wind direction only reaches $215-220^{\circ}$ at the jet maximum height compared to the observed $\sim 190^{\circ}$. The model profiles at $\mathrm{C}$ and $\mathrm{D}$ have a more southerly direction than the A and B profiles that are outside of the jets, which is likely due to the Coriolis effect (see Sect. 3.3.1).

By 15:00 UTC, jet 3 has turned to have a southerly direction over the northern part of the ice shelf and passes very close to the aircraft observation location (Fig. 8c). As mentioned earlier, this is likely due to the Coriolis effect combined with the influence of the southerly winds driven by the pressure gradient (see Fig. 9) that have increased in strength compared to 12:00 UTC. A profile through the jet centre (location E), just $20.7 \mathrm{~km}$ away from the location B, shows that the wind directions at the jet maximum height and throughout the heights sampled by the aircraft are very similar to those observed, as is the height of the maximum wind speed (Fig. 10).

This suggests that the observed jet may have looked somewhat similar to the simulated jet 3 , which emanated from halfway down the Larsen $\mathrm{C}$ Ice shelf $\left(68.5^{\circ} \mathrm{W}\right)$ and experienced considerable northwards progression. The wind speed at this height, though, is somewhat lower than observed being only $\sim 10.5 \mathrm{~m} \mathrm{~s}^{-1}$, although the height of the maximum is very similar to that observed. The likelihood that the observed jet was generally stronger than the simulated one provides more evidence that the observed jet did not start at the 

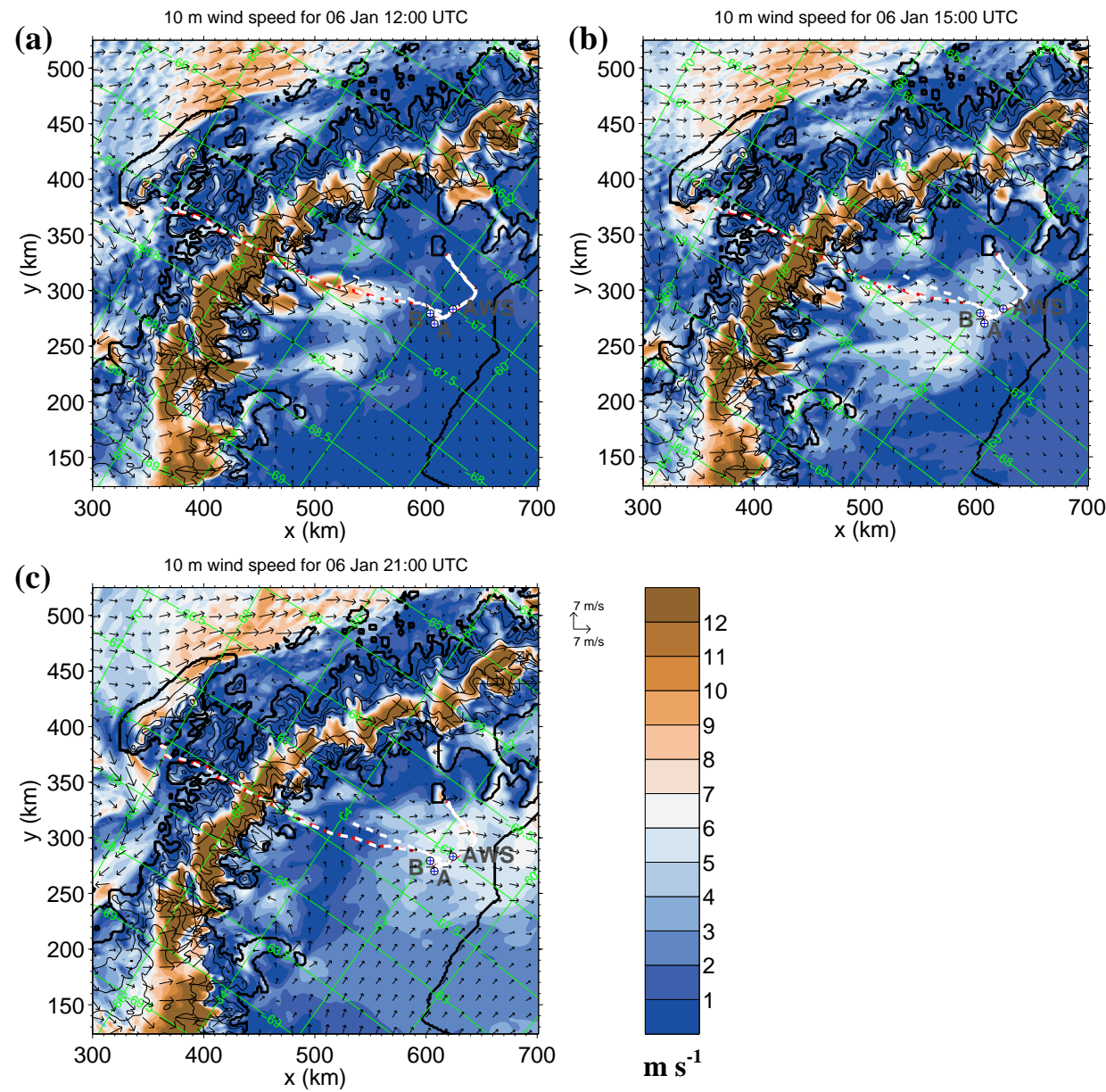

Figure 12. $10 \mathrm{~m}$ wind speeds (colours and vectors) for 6 January at (a) 12:00 UTC, (b) 15:00 UTC and (c) 21:00 UTC.

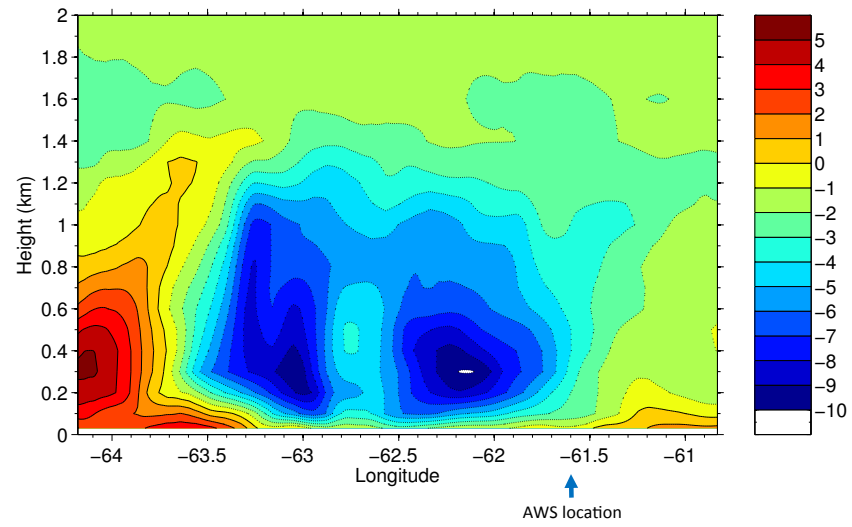

Figure 13. Vertical cross section through the straight black line in Fig. 8c for 15:00 UTC, 6 January. The colours show the component horizontal wind velocity $\left(\mathrm{m} \mathrm{s}^{-1}\right)$ in a direction perpendicular to the line. Positive values indicate the component directed out of the page in an approximately northerly direction. The location of the AWS is also marked. northern part of the ice shelf in a similar manner to the simulated jets 1 and 2 , and therefore probably looked more like the modelled jet 3 . This is because stronger winds would lead to an even more pronounced Coriolis effect than that in the model and therefore would be likely to prevent the winds from reaching the observation location. This conclusion is also corroborated by the aircraft observations made during legs made at constant heights above the ice shelf surface (see Appendix A

Overall, the aircraft comparisons suggest that the model is producing a realistic jet in terms of vertical structure and location, but is somewhat underpredicting the speed of the jet. Also, since the simulated jets have died down by the time of the observations, either the duration of the modelled jet is too short, or the jet occurs too early. This is discussed in more detail in the next subsection.

\subsubsection{Assessment of the model over longer timescales through comparison to the AWS time series}

We now discuss how the föhn jets evolved over time in the model and also in reality. For the latter we use insight gained 

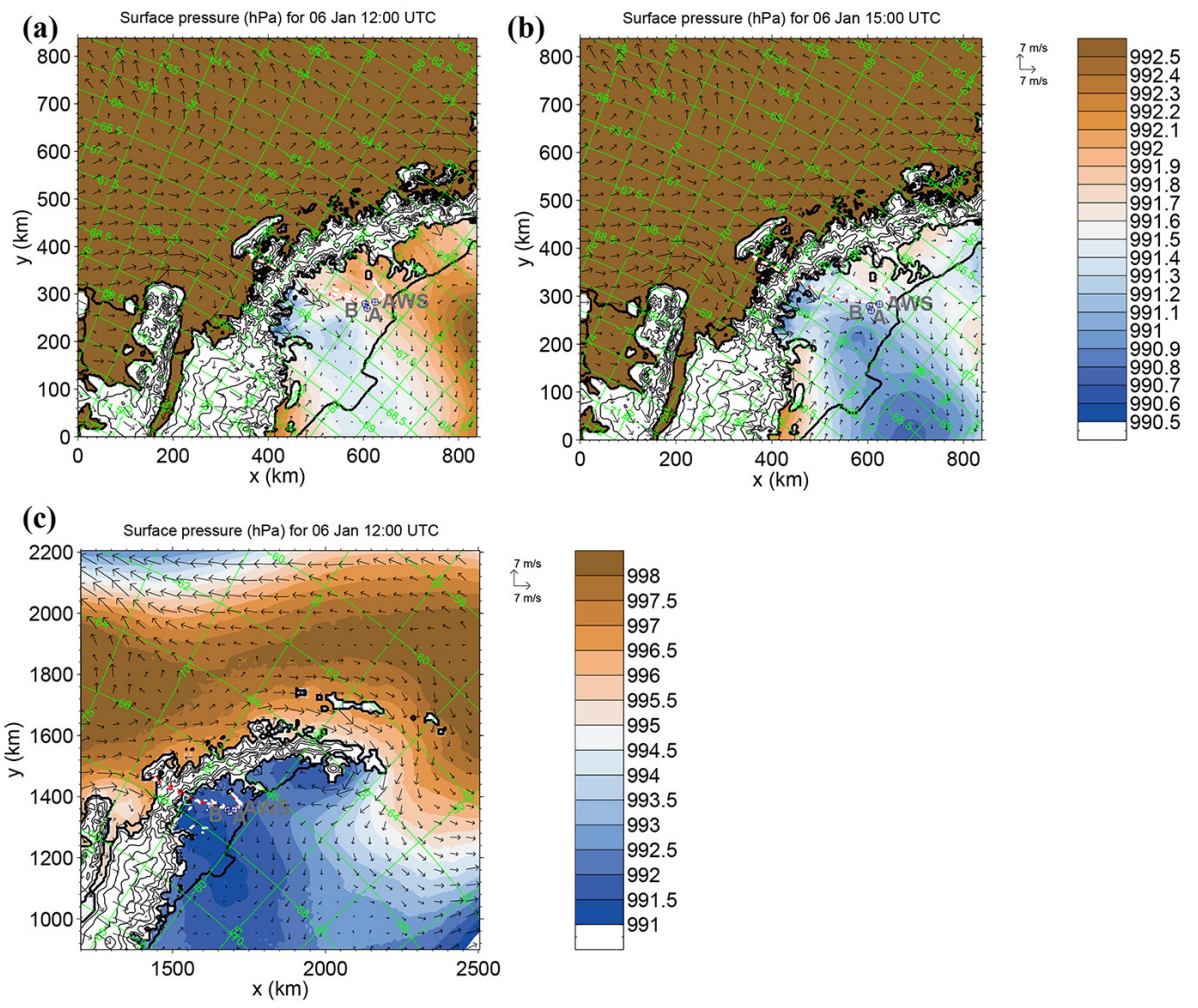

Figure 14. Surface pressure (colours; hPa) and 10 m wind vectors for 6 January. (a) and (b) show WRF domain 3 at 12:00 and 15:00 UTC, respectively, and (c) shows a close up of domain 2 at 12:00 UTC.

from automatic weather station (AWS) near-surface wind speed and direction data, which also helps to assess the realism of the model evolution. The AWS was located in the north-eastern part of the Larsen ice shelf at $67.0^{\circ} \mathrm{S}, 61.6^{\circ} \mathrm{W}$.

The wind speed and direction time series taken near the ice shelf surface by the AWS are shown in Fig. 11a and $\mathrm{b}$, respectively, along with those from the model for $10 \mathrm{~m}$ above the surface at the same location. The AWS shows that there was a large increase in the measured wind speed after 18:00 UTC, 6 January from the low values of $1-4 \mathrm{~m} \mathrm{~s}^{-1}$ before this. The wind speed increased to a peak of $11.9 \mathrm{~m} \mathrm{~s}^{-1}$ at 03:20 UTC, 7 January. This wind increase was accompanied by a gradual change in the wind direction from $330^{\circ}$ (approximately northwesterly) through to westerly and reaching round to northeasterly by around 12:00 UTC, 7 January. A broadly similar wind direction change was produced by the model and in both the model and the observations the change in wind direction is quite precisely coincident with the start of the increase in the wind speed.

However, the increase in wind speed seen in the model was much less than that observed by the AWS, which is perhaps to be expected given the underprediction of the wind jet at $\sim 300 \mathrm{~m}$ by the model, as discussed in Sect. 3.4.1. Some of this underprediction may have also been due to the fact that the modelled jets died down prematurely so that the wind speeds could not build up to levels as high as in reality.
Another discrepancy is that the modelled wind direction starts to quickly rotate towards southwesterly (from being approximately northerly) at $\sim$ 09:00 UTC, whereas the shift in wind direction in the AWS data starts at $\sim$ 18:00 UTC. Thus, there appears to be a time difference of $\sim 9 \mathrm{~h}$ between the onset of changes in the model and those observed by the AWS. A similar time difference is seen for the peak wind speed times. This suggest that a similar evolution of the pressure field over the ice shelf may have occurred in the model and in reality, but at an earlier time in the model.

The eastward movement of the small low-pressure system over the ice shelf seen in Fig. 14a and b may be related to the movement of the larger low-pressure system over the Ronne ice shelf (as seen in Fig. 2). It is possible that this system shifted prematurely in the model compared to reality and was responsible for the influx of southerly winds onto the ice shelf giving rise to the earlier change in $10 \mathrm{~m}$ wind speeds and direction compared to the AWS. Figure $2 b$ shows that the movement of the low-pressure system has resulted in the winds on the west of the Peninsula shifting so that they no longer impact perpendicularly to the ridge. It seems likely that this may have caused the cessation of the föhn jets since föhn flow generally requires winds that are close to perpendicular to the ridge. If the winds shifted early in the model compared to reality then this may have also caused the early cessation of the föhn jets. 
However, it is difficult to ascertain for sure whether there was a timing discrepancy between the model and reality for these large-scale systems. Wind data at upper levels (above the mountain ridge height) would be useful for this since the flow is likely to be less variable and hence more representative of the larger scale situation. Unfortunately, only brief observations at such altitudes are available. For the aircraft observations made above the ice shelf at around $3000 \mathrm{~m}$, the eastward flight leg (the earliest leg at around 20:07 UTC) and the westward leg (22:23 UTC) were only $2.25 \mathrm{~h}$ apart, whereas what is ideally needed is a longer-term time series. Comparisons with the model at the time of the earlier leg do show that the model pressure was $1.8 \mathrm{hPa}$ lower than the observed mean over the leg and the wind direction was around $20^{\circ}$ too low. These are both consistent with the upper situation changing too early in the model since the modelled pressure was dropping and winds rotating towards the south in the model. However, given the small margins involved, it is likely that instrument uncertainties could also account for these differences. Comparisons to the surface pressure time series at Rothera (not shown) reveal a similar decrease in pressure between the model and observations after 00:00 UTC, 6 January, with no clear evidence of a timing issue. One difference, though, is that the observed pressure drops in a "step change" manner between 00:00 UTC, 6 January and 00:00 UTC, 7 January with fairly constant pressure in between, whereas the modelled change is more gradual.

Thus there is some evidence that there are discrepancies with the pressure systems and upper-level winds of the model compared to reality. This would point towards a lack of accuracy with the large-scale analysis that drives the model boundary conditions and upper-level nudging, which in turn may affect the föhn winds. However, given the evidence available, this is fairly speculative and it is possible that there were other causes for the timing differences seen in the lowlevel winds between the model and observations. It should also be borne in mind that the change in upper-level wind direction over the period during which the jets ceased was quite small; the wind direction was $237^{\circ}$ at 06:00 UTC, 6 January and reduced by only $37^{\circ}$ by 12:00 UTC, 7 January. Thus the margins of any error in the analysis are likely to be small, although the results here suggest that such small upper wind direction changes may be important for determining whether föhn flow occurs or not. Also, a timing difference of approximately $9 \mathrm{~h}$ is fairly small given the overall timeframe of the existence of the jets.

In summary, there are some differences between the model and the observations, but overall the agreement is good and gives confidence that the modelled jet behaviour was similar to reality in many aspects.

\subsection{Using the model jet evolution to interpret the AWS time series}

The good agreement between model and reality described in the previous section increases confidence in the use of the modelled circulation patterns to give an idea of what the real circulation was like and to interpret the AWS time series, which is done in this section.

Figure 12a shows that at 12:00 UTC, 6 January the model jets close to the ridge, which had maximum wind speeds at $\sim 300 \mathrm{~m}$, are also associated with strong wind speeds at $10 \mathrm{~m}$. However, it can also be seen from this figure and from Fig. 14a that at this time the wind direction further east, where the AWS is located, and also along the eastern edge of the ice shelf, is approximately northwesterly. The surface pressure fields (Fig. 14a) show that this flow is roughly consistent with the isobars of the small low-pressure circulation in the middle of the ice shelf and with those of the high-pressure ridge to the east. Figure $14 \mathrm{c}$ shows the surface pressure over the second model domain and suggests that the influence of northerly winds over the AWS region in the model is the result of winds that traveled at low levels around the northern tip of the Peninsula, where they then rotated strongly in association with a low-pressure circulation on the south side of the Peninsula and travelled south towards the ice shelves.

In the simulation the circulation patterns start to change after 12:00 UTC, so that by 15:00 UTC the low-pressure circulation over the ice shelf is further east and has intensified (Fig. 14b). The model wind direction over the AWS is closer to westerly at this time. Figure $12 \mathrm{a}$ and $\mathrm{b}$ suggests that the area of higher wind speed over the AWS at 15:00 UTC is due to wind that emanated from locations further north along the Peninsula mountains (jets 1 and/or 2), and travelled approximately towards the north-east. However, the even higher winds associated with jet 3 have not yet reached the AWS region by 15:00 UTC for the height of $10 \mathrm{~m}$ (Fig. 12b) like they have at $300 \mathrm{~m}$ (see Fig. 8c). This is further demonstrated in Fig. 13, which shows a vertical cross section taken at 15:00 UTC, 6 January along a line passing over the AWS location and orientated west to east, such that it is perpendicular to the axis of the jets at this time (see Fig. 8c for the location of the line). The north-south horizontal component shown in the plot reveals much lower wind speeds near the surface compared to those in the jets. A reversed wind direction to the west and east of the jets can also be seen. The modelled differences between the $10 \mathrm{~m}$ and $300 \mathrm{~m}$ winds are also corroborated by the aircraft observations made at constant heights close the surface, which are described in Appendix A.

It is clear that the modelled jets show stronger winds at $300 \mathrm{~m}$ than they do at $10 \mathrm{~m}$ in the regions just downwind of the ridge where the jets emanate. However, at the location of the AWS this disparity is much greater. We speculate that this is due to the fact that the initial lower wind speeds at $10 \mathrm{~m}$ 
would lead to less Coriolis turning than the stronger wind jets at $300 \mathrm{~m}$. This would mean less northerly progression in the face of the northwesterly winds at the eastern edge of the ice shelf associated with the pressure gradient.

The AWS region at $10 \mathrm{~m}$ eventually came under the influence of the jet 3 winds at around 21:00 UTC (Fig. 12c) and led to the peak in winds over the AWS region seen in the model time series (Fig. 11a). This was concurrent with the background wind direction associated with the pressure gradient becoming southerly. By this time there were no more modelled jets emanating from the Peninsula and the winds at all heights were beginning to die down and move eastwards and away from the ice shelf.

It seems likely that a similar situation occurred in reality given the similar evolution in wind direction between the model and the AWS observations, as demonstrated in Fig. 11b. The AWS also showed winds from the north before the onset of the higher strength winds suggesting that a similar circulation to that in the model was preventing some of the strong near-surface jets from reaching the AWS region. Also, by the time of the peak AWS wind speed measurement (03:20 UTC, 7 January), the AWS wind direction had rotated to $\sim 200^{\circ}$, i.e. almost from the south. This suggests that the near-surface winds traversed north across the ice shelf in a similar manner to the modelled $10 \mathrm{~m}$ winds associated with jet 3. At earlier times, e.g. at 21:50 UTC, 6 January when the AWS was registering wind speeds of $10.3 \mathrm{~m} \mathrm{~s}^{-1}$ and a wind direction of $\sim 300^{\circ}$, the near-surface winds were likely to have been linked to jets similar to the modelled jets 1 and 2 .

The maximum modelled wind speed over the AWS region came later than the maximum intensity of the main jets, and it is likely that this was also the case in reality. In that case the jets may have been in existence for some time before the AWS registered the wind speed increase suggesting that its location is not ideal for detecting föhn jet events.

\subsection{Potential temperature cross sections and föhn thermodynamics}

We now describe and discuss some details of the flow structure and thermodynamics by examining vertical cross sections of potential temperature and wind speed taken roughly parallel to the flow (perpendicular to the ridge).

Figures $15 \mathrm{a}$ and $\mathrm{b}$ show vertical cross sections along the black straight line drawn in Fig. 8. Shown are the potential temperature and the component of the horizontal wind speed perpendicular to the ridge at 09:00 UTC, 6 January. The latter is approximately equal to the east-west wind component since the ridge is aligned almost in a north-south direction and will hereafter be denoted as $U$. At this time the cross section passes through the centre of jet $\mathrm{B}$. The figure shows that there are some large amplitude wave disturbances to the lee side of the mountain. The potential temperature contours are packed tightly above the lee slope whilst descending down the mountain and are co-located with the high downslope winds near the lee surface. Midway down the lee slope of the mountain, the adiabats suddenly move back upwards in a manner akin to a hydraulic jump in hydraulic flow (e.g. Houghton and Kasahara, 1968; Durran, 1986). It is clear that air is descending from mid-tropospheric levels towards the surface, which will cause a large degree of adiabatic warming and wind acceleration. Above the mountain, large amplitude gravity waves are present that appear to break at around $2.5 \mathrm{~km}$ altitude where there is a region of well-mixed air in which the wind speed is low.

Upwind of the mountains there are several layers with different degrees of stratification. The air below $\sim 400 \mathrm{~m}$ is fairly well mixed and is topped with an inversion between 400 and $1200 \mathrm{~m}$. As the mountains are approached the adiabats associated with the upper part of the inversion start to rise up and over the terrain. To the west side of the cross section there is a mixed layer above the inversion that reaches up to $\sim 1.6 \mathrm{~km}$. Above that height the air is approximately constantly stratified. Thus the air upstream of the mountains during the wind storm contains a combination of inversion and mixed layer regions as well as regions of approximately constant stratification.

A Froude number can be calculated for the mean upstream conditions that helps to characterise the nature of the flow:

$F_{0}=\frac{U_{0}}{N H}$.

Here $U_{0}$ is the characteristic upstream wind speed, $N$ is the upstream Brunt Väisälä frequency and $H$ is the mountain height. $F_{0}$ defined in this way is equivalent to the inverse of the non-dimensional mountain height, $\hat{h} . F_{0} \ll 1$ (and therefore $\hat{h} \gg 1$ ) is associated with blocking of the low-level flow so that it is diverted around the obstacle rather than up and over it. Hunt and Snyder (1980) showed that for an isolated hill the height below which the flow is blocked is approximately given by

$z_{d}=H\left(1-\alpha F_{0}\right)$

with $\alpha \sim 1$.

Calculating these values for the profile at the western edge of the cross section shown in Fig. 15 by using the mean cross-section component wind speed between the surface and a height of $2 \mathrm{~km}$ and by calculating $N$ over the same heights gives $N=0.0158 \mathrm{~s}^{-1}, F_{0}=0.27, \hat{h}=3.8$ and $z_{d}=1100 \mathrm{~m}$. Thus strong low-level blocking would be expected and is indeed observed in the simulation. Calculations of streamlines from the flow field (not shown) and examination of the potential temperature contours suggest a value for $z_{d}$ of around $1100 \mathrm{~m}$ in agreement with Eq. (3). Orr et al. (2008) suggest that the parameter $\alpha$ in Eq. (3) will depend on the aspect ratio of the orography and the Coriolis parameter, so the actual value of $z_{d}$ may differ from that calculated from Eq. (3) with constant $\alpha$.

The fact that strong downslope winds that result in surface warming on the lee side are simulated by the model in this 

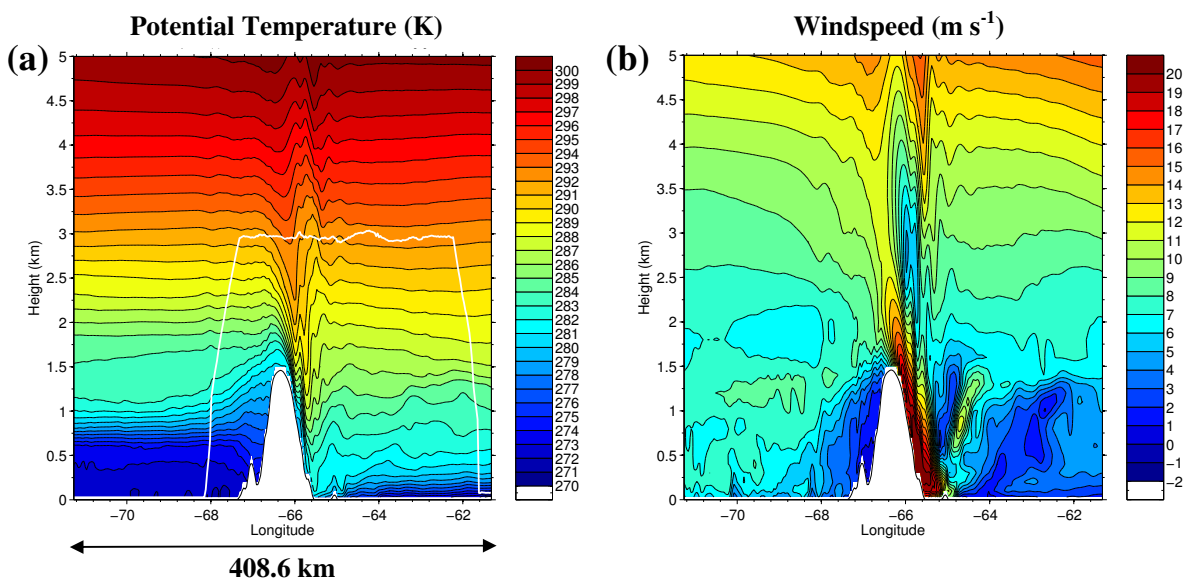

Figure 15. Vertical cross sections of potential temperature (a) and horizontal component wind speed (b) along the straight line in Fig. 8a for 09:00 UTC, 6 January. The white solid line in (a) shows the height of the aircraft projected onto the longitude of the cross section.

case is interesting because of the low upstream value for $F_{0}$ and associated low-level blocking. Many previous studies of the effects of föhn flow over the AP (Marshall et al., 2006; Orr et al., 2004, 2008; van Lipzig et al., 2008) have implied that such flow would not cause a warming of the surface of the Larsen ice shelves if the upstream flow was significantly blocked (i.e. if $F_{0} \ll 1$ ). In those studies, the suggestion was made that, for example, the upstream wind speed would need to increase in order to increase $F_{0}$ and allow the warming to occur. The case presented here indicates that strong lee-side warming can also occur under blocked flow regimes, suggesting that the relationship between upstream wind speed and lee-side warming may not be as simple as envisioned in the studies referenced above.

Strong downslope flow and surface warming orographic flows occurring in situations with low upstream $F_{0}$ have been discussed in the literature in the past (see Durran, 1990, for a review). Perhaps most notably for this case, Smith (1985, hereafter S85) and Smith (1989) suggest that upstream blocking can create an "effective surface" that acts to reduce the effective height of the mountain on the windward side. The one layer model of the former was generalised to allow two upstream layers of differing stability in Smith and Sun (1987, hereafter SS87). The theoretical arguments of S85 and SS87 suggest that this reduction in effective upstream mountain height might be very important in facilitating the strong downslope winds on the lee side because the theory allows only certain configurations of $\hat{h}$ and other parameters in order for such winds to occur. Evidence from numerical models that support the ideas of S85 and SS87 and the requirement of specific parameter configurations is presented in Durran and Klemp (1987).

In addition, these theoretical models require a region of stagnant air above the lee slope that acts to channel the flow beneath it down the lee slope. Indeed, such a stagnant, low wind speed, turbulent region exists above the lee slope of the simulated fields centred at a height of around $2.75 \mathrm{~km}$ (Fig. 15b). It was suggested in S85 that this could occur through the breaking of gravity waves propagating upwards above the lee slope. Such wave breaking can occur due to the presence of a critical layer where there is a rapid reversal in wind direction or a rapid reduction in stability, although this is not the case with the case study presented here. However, linear hydrostatic theory predicts that for a bellshaped mountain maximum steepening of the streamlines of the mountain waves occurs at a height of

$z_{\text {crit }}=0.75 \lambda$,

where $\lambda=2 \pi U / N$ is the vertical wavelength (Peltier and Clark, 1979). If the mountain is sufficiently large then the steepening can become critical so that the streamlines become vertical and the wave is likely to overturn and break. Linear hydrostatic theory dictates that vertical streamlines occur when $\hat{h}$ reaches unity, although Miles and Huppert (1969) suggested a lower value $(\hat{h}=0.86)$ from the application of a non-linear lower boundary condition for hydrostatic waves over a bell-shaped mountain. Thus the $\hat{h}$ value of 3.8 in the AP simulation should be more than sufficient to allow wave overturning above the lee slope. Using the same parameters as before yields a $z_{\text {crit value of }} 2.8 \mathrm{~km}$. This is very close to the location of the well-mixed region seen in Figs $15 \mathrm{a}$ and $\mathrm{b}$ suggesting that wave breaking was occurring there and played a key role in allowing the strongly accelerated downslope flow as described in S85 and SS87.

In the AP simulation presented here, the upstream stability profile above the "effective surface" $(\sim 1100 \mathrm{~m})$ consists of a well-mixed layer with a region of constant stratification above. Thus the two-layer model of SS87 is perhaps more appropriate than the single layer model described in S85.

In the next subsection, we examine the upper-level aircraft observations taken along the cross section to assess how well the modelled flow structure matches that of the real flow. 


\subsubsection{Upper-level aircraft comparisons along the cross section}

Figure 16 shows comparisons between model and aircraft quantities taken along approximately west to east cross sections at a height of $2900 \mathrm{~m}$. The model cross section is taken over a straight line that is to the north of that shown in Fig. 15 in order to approximately lie over that of the aircraft trajectory. The aircraft observations of $U$ show a reduction in wind speed downwind of the crest of the ridge. This corresponds to the position of the stagnant, turbulent region that was also seen in the model and was hypothesised to have been caused by wave breaking. The model and aircraft component wind speeds are very similar except there is a slightly quicker return to the upwind values in the observations (when moving from west to east). The vertical wind observations also show upward motion in the stagnant region, along with enhanced turbulence, which also extends downwind. This is consistent with the presence of gravity waves which are breaking in the low horizontal wind speed region, consistent with the theories of S85 and SS87. The model results show similar patterns, except with much lower magnitude vertical winds. One possible reason for this is a lack of vertical and horizontal model resolution. However, the reader is also reminded that different times are being compared for the model and the aircraft due to the likelihood that the WRF simulation has timing errors. The potential temperature in the model and the observations both show a decrease within the region of low $U$ followed by a gradual increase downwind. This decrease is consistent with the position of the hydraulic jump-like behaviour of the adiabats in the model cross section in Fig. 15. Overall, except for the vertical wind, there is good agreement between the model and the observations suggesting that the model is capturing the flow structure in a realistic manner, but is unable to capture smaller scale turbulence due to model resolution restrictions. The agreement for the flow structure might suggest that explicitly capturing the sub-model gridscale detail may not be necessary in order to simulate the processes that are important in determining the flow structure.

\subsubsection{Discussion on the modelling and prediction of föhn events over the Antarctic Peninsula}

The similarity of the features of the case simulated here to those in SS87 and the good comparison to the observations suggests that, in addition to simple linear models for high $F_{0}$ flow, the SS87 model and other related models should be considered when attempting to predict whether strong downslope flow and leeward surface heating is likely to occur over the AP in low $F_{0}$ conditions. This may require analysis of whether and at what height wave breaking is likely to occur above the lee slope. Such alternative models should also be examined when considering how future changes in wind speed, stability, etc. during a changing climate might affect föhn frequency. However, it should be noted that the models of S85 and SS87 only describe the final state of the downslope winds, rather than how the atmosphere evolved to get there. Thus, whether the fairly restrictive configuration of parameters described in those papers needs to be initially met in order for windstorms to occur, or whether the atmosphere is likely to evolve into the required state through feedback mechanisms is unknown. Further analysis of such a model is beyond the scope of this study and is therefore left for future work.

It should also be noted that windstorms have been shown to occur in situations with no wave breaking when there is a layer of strong stability below a layer of lower stability (Durran, 1986, 1990) and so these situations should also be considered for the AP. However, given the very large mountain height of the AP ridge, it seems likely that large amplitude induced wave breaking will often be a feature in this region. Durran (1990) gives some guidelines for forecasting windstorms, although there is still a great deal of uncertainty about how to do this.

Finally, the simulations of flow over the Antarctic Peninsula presented in Orr et al. (2008) showed a case where there was upstream blocking in a similar flow regime to that in our case ( $\hat{h}=3.0$ compared to $\hat{h}=3.8$ in our case) and with a similar upstream vertical stratification pattern. However, in Orr et al. (2008) there was no descent of warm, accelerated air on the leeward side down to the surface in contrast to our case. It is difficult to say for sure why the two outcomes are so different given the complexity of such flows and the incompleteness of the knowledge of them, as well as the possibility of time dependent behaviour. Although, one key difference between the two simulations is that the horizontal resolution used in Orr et al. (2008) was $12 \mathrm{~km}$, compared to the $1.875 \mathrm{~km}$ used in our study. This could conceivably have have led to poorly represented gravity waves in the latter, which in our study had a horizontal wavelength of around $60 \mathrm{~km}$ and were shown to have been vital for the lee flow development. However, examination of the lowest resolution $(30 \mathrm{~km})$ nest from our simulation reveals that warm air descent onto the Larsen ice shelf does occur despite the resolution being much lower than that in Orr et al. (2008). One other possibility is that the vertical resolution is also important; our simulation used 81 vertical levels whilst that of Orr et al. (2008) used only 38. Vertical resolution is likely to be important for correctly capturing the rapid changes in stratification with height that are known to be important for lee flow development. Recent $1.5 \mathrm{~km}$ resolution simulations presented in Elvidge et al. (2014) also showed the occurrence of föhn flow in blocked upwind conditions, which corroborates our results.

\subsubsection{The time evolution of the upstream conditions}

We now briefly discuss how upstream conditions changed during the simulation, again for the profile at the left edge 

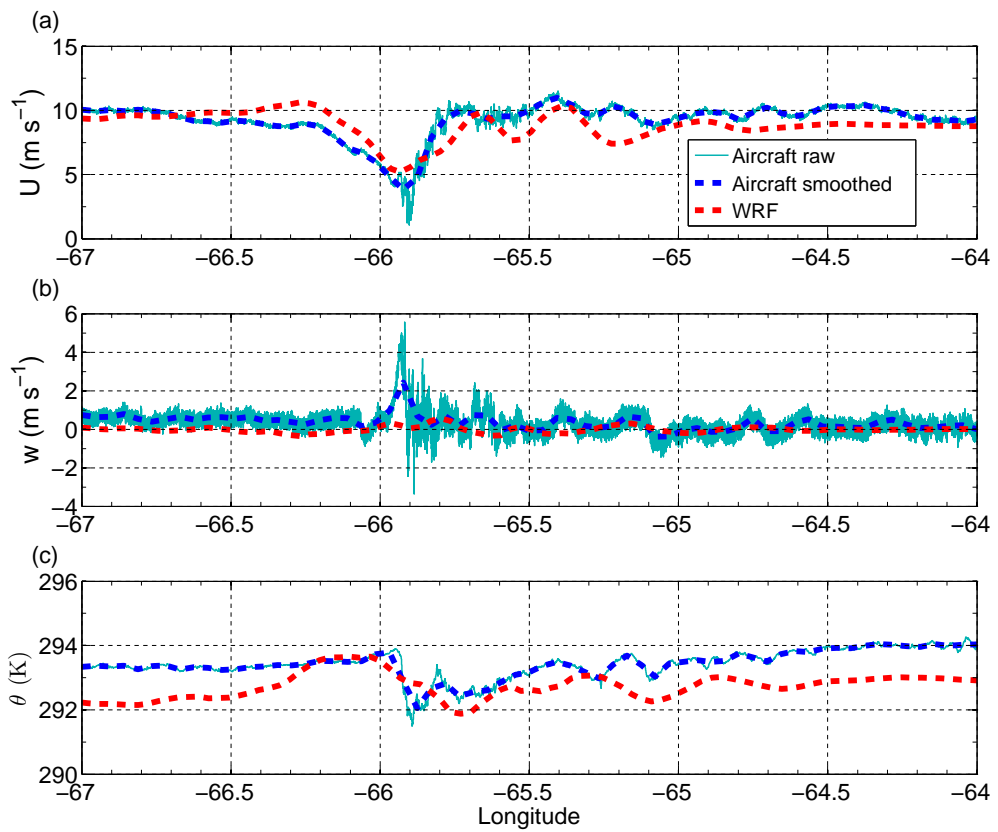

Figure 16. A comparison between the aircraft and WRF model at a height of $2900 \mathrm{~m}$ along similar west to east transects. For the WRF model, the transect is for 09:00 UTC, 6 January. For the aircraft the observations were made between 19:31 and 20:14 UTC, 6 January. The aircraft data has been binned into $2 \mathrm{~km}$ segments in order to match the horizontal resolution of the model ("Aircraft smoothed" on the legend). The original high-frequency data is shown as a thin line labelled "Aircraft raw". Shown are (a) the component horizontal wind speed, (b) the vertical wind speed and (c) the potential temperature.

of the same cross section as above. Figure 17 shows time series of various quantities at this location. At the start of the simulation (00:00 UTC, 5 January) $F_{0}=0.19, \hat{h}=5.2$, suggesting stronger low-level blocking than at the time of the main jets. The lower $F_{0}$ value at the simulation start is due to $U_{0}$ being lower ( 4.4 vs. $6.3 \mathrm{~m} \mathrm{~s}^{-1}$ ) since the stability value is actually slightly lower at this time $(N=0.0152$ vs. $0.0158 \mathrm{~s}^{-1}$ ). For the initial conditions the ECMWF analysis model exhibits a wide jet that reaches down to low levels. The realism of the ECMWF analysis can be questioned because of the unrealistic terrain height due to poor horizontal resolution relative to the steepness of the AP. However, the potential temperature structure looks similar to that shown in Fig. 15 and the wind direction is perpendicular to the ridge, suggesting that conditions were favourable for jet formation. As mentioned earlier, in the WRF simulation this initial near-surface jet dies down, but then builds up again after 03:00 UTC, 6 January. The die down of the jets after the start of the simulation is associated with a rapid change in wind direction and increase in $N$. However, this is likely due to model spin-up.

The main jets start at around 03:00 UTC, 6 January, but begin to die down in intensity shortly afterwards, at around 15:00 UTC. By 06:00 UTC, 7 January they have mostly dissipated. From Fig. 17 it can be seen that there are fairly large wind direction changes that coincide with the onset and cessation of the jets. By 03:00 UTC on 6 February, the wind direction is perpendicular to the ridge again $\left(\sim 270^{\circ}\right)$ after being at values $<263^{\circ}$ before that. It then veers sharply to a value of $244^{\circ}$ between 12:00 and 15:00 UTC. The component wind speed is at its largest during the active period of the jets with the largest value occurring at 06:00 UTC, 6 January. This peak in component wind speed is due to the wind direction change rather than a change in the magnitude of the wind speed. However, the changes in $\hat{h}$ are not consistent with a threshold like behaviour that determines whether the föhn jets are active or not, since $\hat{h}$ is slightly larger at 12:00 UTC, 6 January than at 15:00 UTC due to the general decrease in $N$ over the period. This suggests that the change in component wind speed may not be critical in determining the onset and cessation of the jets since wind speed effects would be expected to manifest through $\hat{h}$ changes. The results here suggest that the large wind direction changes at $1 \mathrm{~km}$ between 12:00 and 15:00 UTC are more clearly associated with the cessation of the jets.

Figure $17 \mathrm{f}$ reveals a rapid reduction in relative humidity $(\mathrm{RH})$ at the same time as the wind direction change and cessation of the föhn event. There are indications that the moisture content of the upwind air has implications for blocking (Miglietta and Buzzi, 2001), which might suggest that the change in RH is playing some role in the föhn cessation. However, without some idealised modelling of this case it is probably impossible to say whether the change in RH had any causal effect on the flow, or whether it was a symptom 
(a)

(b)
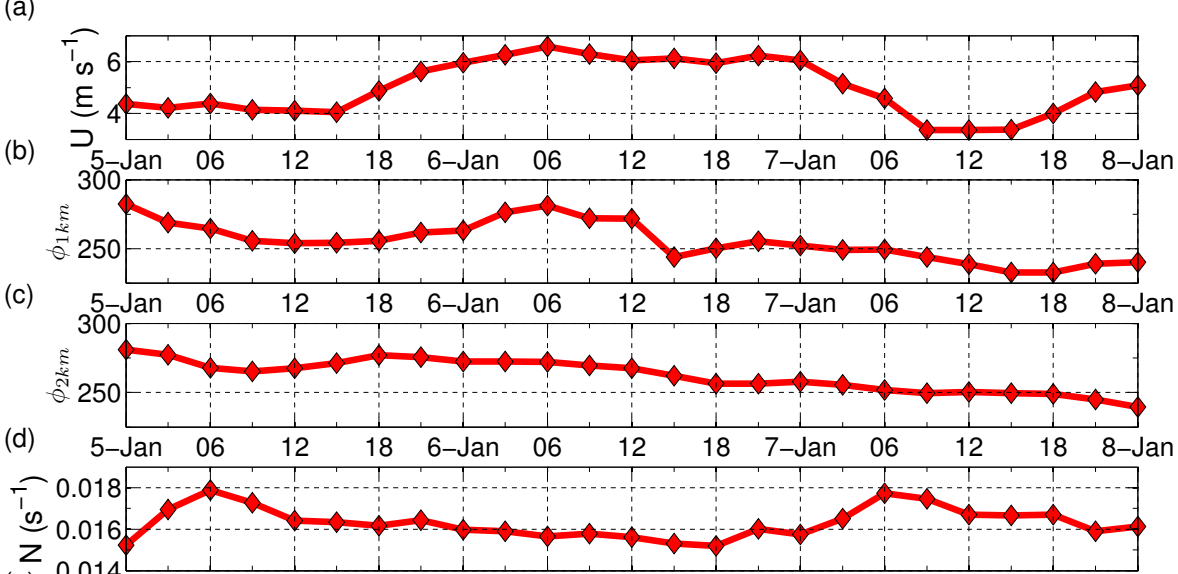

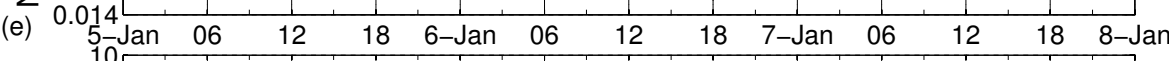

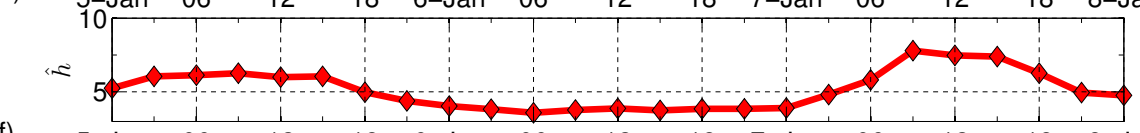

(f)

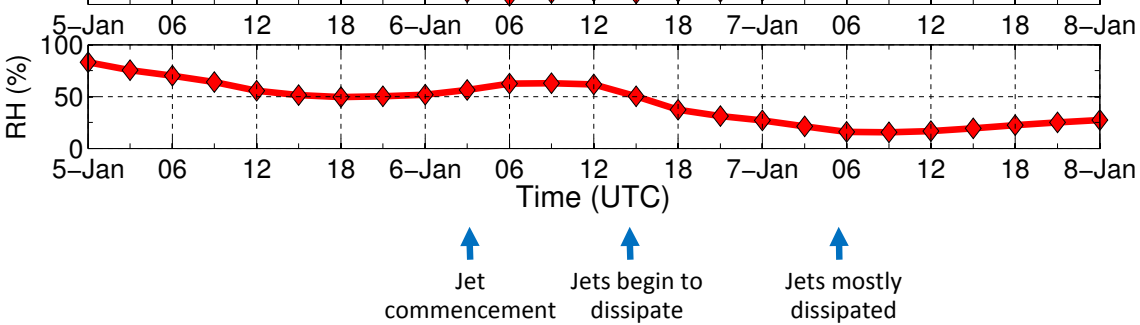

Figure 17. Time series of various quantities taken from the profile at the lefthand edge of the cross section in Fig. 15. (a) shows the component horizontal wind for the cross section averaged between heights of 0 and $2 \mathrm{~km}$; (b) and (c) show the wind direction $(\phi)$ at heights of 1 and $2 \mathrm{~km}$, respectively; (d) shows that Brunt Väisälä frequency; (e) shows the non-dimensional mountain height; and (f) shows the relative humidity (RH) at a height of $2 \mathrm{~km}$. Also marked are notable times for the development of the near-surface jet on Larsen C.

of the meteorology changes. The shift of the wind direction upwind of the mountain towards southerly would also be associated with reduced relative humidity since the air would then be coming from the dry continent rather than the moist oceanic regions. Although the same lack of proof of causality can also be said for the wind direction effect. Further work would be required to answer this, which is beyond the scope of our study.

By 15:00 UTC, 6 January, the upstream wind direction has changed so that it is no longer perpendicular to the ridge. The potential temperature profile at this time is very similar up to around $1.2 \mathrm{~km}$ with low-level blocking still evident to around the same level (not shown). However, the mixed layer between $1.2 \mathrm{~km}$ and $1.5 \mathrm{~km}$ is now more stratified and $N=0.0167 \mathrm{~s}^{-1}, F_{0}=0.22, \hat{h}=4.6$, so that the upwind air is more stable and more conducive to low-level blocking. The disappearance of the mixed layer at this time suggests that it was associated with the föhn flow.

\section{The effects of the föhn jets on surface melting and the surface energy budget of the Larsen ice shelves}

The good match between the model and observations presented so far give confidence that the development and evolution of the modelled jets are similar to that of the real jets, which might suggest that the modelled effects of the jets on the ice shelf surface will also be realistic. However, we also acknowledge that the interactions between the jet dynamics and the radiative fluxes will be somewhat different from those in reality due to the timing issues described earlier. Also, the modelled impact of the jets upon the ice surface will be dependent upon the surface scheme of the model, which is discussed later.

Marshall et al. (2006) suggested that increased frequencies of föhn events over the AP due to strengthening westerlies may have been the cause of rapid warming on the east side of the AP in the austral autumn and summer, with the implication that this contributed to the collapse of the Larsen B ice shelf. Here we investigate the effect of the simulated föhn event on the amount of ice surface melting on Larsen C, since there is evidence that accumulation of meltwater was a major factor in the break-up of Larsen B (Scambos et al., 
Table 1. A comparison of instantaneous flux components of the surface energy balance (SEB) between the model and the aircraft measurements of King et al. (2008) for the "L-shaped" flight leg at $15 \mathrm{~m}$ altitude. See Sect. 4.1 for details. Model results are for 21:00 UTC, whereas the flight leg took place at 20:23 UTC. For this reason calculations using an adjusted model value for SW $\mathrm{J}_{\downarrow}$ have also been provided and the biases were calculated using these values. Since the aircraft did not measure ground heat fluxes (GH) model GH has been to set to zero for the overall model melt $(M)$ calculation and its bias.

\begin{tabular}{lrrrr}
\hline & Aircraft & $\begin{array}{r}\text { Model, } \\
\text { original }\end{array}$ & $\begin{array}{r}\text { Model, } \\
\text { adjusted }\end{array}$ & $\begin{array}{r}\text { Bias for } \\
\text { adjusted model }\end{array}$ \\
\hline $\mathrm{SW}_{\downarrow}\left(\mathrm{W} \mathrm{m}^{-2}\right)$ & 568.0 & 522.5 & 583.5 & 15.5 \\
$\mathrm{SW}_{\uparrow}\left(\mathrm{W} \mathrm{m}^{-2}\right)$ & -441.0 & -365.8 & -408.5 & 32.5 \\
$\mathrm{SW}_{\text {net }}\left(\mathrm{W} \mathrm{m}^{-2}\right)$ & 127.0 & 156.8 & 175.1 & 48.1 \\
Albedo & 0.8 & 0.7 & 0.7 & -0.1 \\
& & & & \\
$\mathrm{LW}_{\downarrow}\left(\mathrm{W} \mathrm{m}^{-2}\right)$ & 237.0 & 240.2 & 240.2 & 3.2 \\
$\mathrm{LW}_{\uparrow}\left(\mathrm{W} \mathrm{m}^{-2}\right)$ & -316.0 & -299.9 & -299.9 & 16.1 \\
$\mathrm{LW}_{\text {net }}\left(\mathrm{W} \mathrm{m}^{-2}\right)$ & -79.0 & -59.7 & -59.7 & 19.3 \\
$R_{\text {net }}=\mathrm{SW}_{\text {net }}+\mathrm{LW}_{\text {net }}\left(\mathrm{W} \mathrm{m}^{-2}\right)$ & 48.0 & 97.1 & 115.4 & 67.4 \\
$\mathrm{SH}\left(\mathrm{W} \mathrm{m}^{-2}\right)$ & & & & 1.1 \\
$\mathrm{LH}\left(\mathrm{W} \mathrm{m}^{-2}\right)$ & 13.0 & 1.1 & -2.9 \\
$\mathrm{GH}\left(\mathrm{W} \mathrm{m}^{-2}\right)$ & -9.0 & -2.9 & -2.9 & 6.1 \\
$M\left(\mathrm{~W} \mathrm{~m}^{-2}\right)$ & N/A & -14.8 & 0.0 & N/A \\
\hline
\end{tabular}

2000, 2004; van den Broeke, 2005) and so could potentially threaten the stability of Larsen C.

It is interesting to consider the causes of the differences between the melting on Larsen B, where a dramatic ice shelf collapse has already occurred, and that over the southern regions of Larsen $\mathrm{C}$, where collapse seems very unlikely at present. However, in a warmer climate there is the potential for melting rates in the south to become closer to those occurring over Larsen B at the present time, which may increase the risk of melt water induced break-up. Understanding the differences between the energy budgets of the two regions may provide some insight into what would be required for this to happen. However, it has to be borne in mind that the conclusions drawn from a single case study such as this may not necessarily be representative of the general situation.

Whilst the surface scheme in the WRF model will not capture many of the details of the ice shelf surface it should provide some useful basic insight into how the atmosphere and surface are likely to interact during a föhn flow and during melting periods. Potential deficiencies in the representation of the WRF ice surface and sub-surface are discussed in Sect. 5.

\subsection{Instantaneous flux comparisons between the model and aircraft}

First of all we compare the surface energy balance (SEB) flux components from the model to those observed by the aircraft in order to get some idea of the reliability of the model in this regard. The SEB equation can be written as

$$
M=\mathrm{SW}_{\text {net }}+\mathrm{LW}_{\text {net }}+\mathrm{SH}+\mathrm{LH}+\mathrm{GH},
$$

where $M$ is the energy available for surface ice melting; $\mathrm{SW}_{\text {net }}$ and $\mathrm{LW}_{\text {net }}$ are the net short-wave and long-wave fluxes at the surface; $\mathrm{SH}, \mathrm{LH}$ and $\mathrm{GH}$ are the surface sensible, latent and ground heat fluxes, respectively. The fluxes are in $\mathrm{W} \mathrm{m}^{-2}$ and +ve indicates flux of energy into the surface layer. $M$ is only calculated if the surface temperature is $\geq 0^{\circ} \mathrm{C}$.

King et al. (2008) performed some SEB calculations for the Larsen $\mathrm{C}$ ice shelf based upon the aircraft measurements taken during the flight leg at altitude $15 \mathrm{~m}$ and $67^{\circ} \mathrm{S}$ that was described in Sect. A. Thus the results should be applicable to the modelling results presented here since the same event was being considered, except for the timing differences between model and reality that were discussed in the previous sections. Here we compare the observed aircraft fluxes to those from the model. For the latter averages were taken along the "L-shaped" flight path of the aircraft.

The time of day at which the flight leg took place was at 20:23 UTC (approximately 16:12 LT). The closest model output for comparison is 21:00 UTC. The modelled value of $\mathrm{SW}_{\downarrow}$ at this time will thus be slightly lower than that at the time of the observations. The model value of $\mathrm{SW}_{\downarrow}$ was $522.5 \mathrm{~W} \mathrm{~m}^{-2}$, whereas that observed in King et al. (2008) was $568 \mathrm{~W} \mathrm{~m}^{-2}$. If the model value is adjusted using the ratio of the cosines of the model and observation solar zenith angles then a value of $583.5 \mathrm{~W} \mathrm{~m}^{-2}$ is obtained. The model and observations agree within $2.7 \%$ once this adjustment is made. Thus, for the purposes of the comparison to the 
aircraft in this section the adjusted $\mathrm{SW}_{\downarrow}$ is used. The upwelling short-wave radiative flux is calculated using $\mathrm{SW}_{\uparrow}=$ $-\alpha \mathrm{SW}_{\downarrow}$, where $\alpha$ is the surface albedo for which the original model value is used $(\alpha=0.7)$. Also, the aircraft observation derived calculations of melting did not include an estimate of $\mathrm{GH}$, which in the model was $-14.8 \mathrm{~W} \mathrm{~m}^{-2}$. If the model GH is accurate then this would indicate some degree of underestimate in the melting estimates presented in King et al. (2008). For a fair comparison, we do not include GH in our model calculations in this section. Table 1 summarises the resulting aircraft and model flux components of the SEB, along with the model biases.

King et al. (2008) calculated an overall melting flux of $52 \mathrm{~W} \mathrm{~m}^{-2}$ compared to the model result of $113.6 \mathrm{~W} \mathrm{~m}^{-2}$, which represents a model bias of $+61.6 \mathrm{~W} \mathrm{~m}^{-2}$. The two main reasons for this overestimate can be identified as the model $\alpha$ value being lower than observed and the model upwelling LW flux $\left(\mathrm{LW}_{\uparrow}\right)$ being higher (less negative) than observed. The model $\alpha$ over the ice shelf is a constant 0.7 , whereas the mean $\alpha$ measured by the aircraft was 0.78 . This difference combined with the $\mathrm{SW}_{\downarrow}$ bias leads to a model bias in $\mathrm{SW}_{\text {net }}$ of $+48.1 \mathrm{~W} \mathrm{~m}^{-2}$ relative to the observations.

The downwelling $\mathrm{LW}$ fluxes $\left(\mathrm{LW}_{\downarrow}\right)$ between the model and observations agree within $1.4 \% . \mathrm{LW}_{\uparrow}$ is calculated using $\mathrm{LW}_{\uparrow}=\epsilon \sigma_{\mathrm{SB}} T_{\text {surf }}^{4}$, where $\epsilon$ is the surface emissivity, $\sigma_{\mathrm{SB}}=$ $5.67 \times 10^{-8} \mathrm{~W} \mathrm{~m}^{-2} \mathrm{~K}^{-1}$ and $T_{\text {surf }}$ is the surface temperature. The model $\mathrm{LW}_{\uparrow}$ calculated in this manner is $5.1 \%$ lower than that observed. This bias is almost entirely due to differences in $\epsilon$ because $T_{\text {surf }}=273.15 \mathrm{~K}$ in both the model and observations since the surface is melting. $\epsilon=0.95$ for the model in this region, whereas the observed value was almost one. The overall bias in $\mathrm{LW}_{\text {net }}$ was $+19.3 \mathrm{~W} \mathrm{~m}^{-2}$ and thus the overall bias in $R_{\text {net }}\left(=\mathrm{SW}_{\text {net }}+\mathrm{LW}_{\text {net }}\right)$ is $+67.4 \mathrm{~W} \mathrm{~m}^{-2}$. These comparisons demonstrate the difficulty in modelling the melting flux; small uncertainties in the albedo or emissivity lead to much larger relative errors in the melt flux since the latter is the difference between large terms.

Both the model and the observations show a similar ratio between $R_{\text {net }}$ and $M ; 1.0$ for the model and 0.9 for the aircraft observations. Thus, both results are in agreement that the SW and LW fluxes are likely the most important terms when considering melting fluxes for this event.

The sensible and latent heat fluxes from the model were of lower magnitude than those measured being 1.1 and $-2.9 \mathrm{~W} \mathrm{~m}^{-2}$, respectively, in the model and 13 and $-9 \mathrm{~W} \mathrm{~m}^{-2}$ in the observations, leading to an overall model bias in $\mathrm{SH}+\mathrm{LH}$ of $-5.8 \mathrm{~W} \mathrm{~m}^{-2}$. This could indicate that the modelled direct effect of the jets on the surface was underestimated, perhaps due to the fact that the modelled jets were too weak, as demonstrated earlier. It may also indicate deficiencies in the model parameterisation of surface layer turbulent fluxes; this is discussed in more detail in Sect. 5. However, the bias in $R_{\text {net }}$ dominates the bias in $M$ relative to the $\mathrm{SH}+\mathrm{LH}$ bias.

\subsection{The overall melting during the simulation}

We now go on to calculate overall model surface melt for 6 January and examine how the melt and its components vary with latitude. The times used in the calculations in this section were 12:00, 15:00, 18:00 and 21:00 UTC (local solar time is UTC -4.2). Very little melting occurred outside of these times. Only these times were considered since melting occurred at all locations on the ice shelves for these times, whereas at other times melting occurred at some places, but not others. This allows a fair comparison of the relative contributions to the melting from the different processes for different locations.

To calculate overall melt, the mean melt flux over the above times is first calculated for each location from the instantaneous net surface fluxes using Eq. (5). Surface fluxes were output by the model every three hours and thus the total melting values in $\mathrm{mm}$ of water equivalent (mm w.e.) are given by multiplying the mean flux by $\frac{3 N \times 3600}{L_{\mathrm{f}}}$, where $N$ is the number of output times $(=4)$ and $L_{\mathrm{f}}$ is the latent heat of fusion. Here it assumed that the fluxes are constant between model output times, which will lead to some degree of inaccuracy. Given the results of the previous section, for these calculations the model surface albedo and emissivity values are changed to those observed by the aircraft ( 0.78 and 1.0 , respectively). The ground heat flux predicted by the model is now included.

Figure 18 shows the total snowmelt for domain 3 of the WRF simulation for 6 January only. Note that for these simulations the land-sea mask was out of date since it does not include the collapsed portion of Larsen B. However, this is expected to make a negligible difference to the overall simulation. Melting estimates over the Larsen B region therefore reflect those before the collapse took place. The results show that the total melting is higher for the more northerly sections of the Antarctic Peninsula, such as the Larsen B region and that it generally decreases with distance south. However, the melting on Larsen B was fairly similar to that on the northern sections of Larsen C. However, the pattern is not simply a function of latitude since there are high values towards the AP ridge between 67 and $68.5^{\circ} \mathrm{S}$, but lower values near the east of the ice shelf at these latitudes. This suggests some influence of the warm föhn jets coming down from the ridge.

\subsection{The contribution to melting from different sources}

Figure 19 shows the simulated melting within the ice shelf regions averaged along lines of constant latitude, as well as the contributions to the mean melt rate from the different heat flux sources. In this figure the total melt line has been displaced to read zero at $65.6^{\circ} \mathrm{S}$ for ease of comparison with the other lines. This location will hereafter represent a reference location on the Larsen B ice shelf and is later used for comparison with more southerly points. The mean total melting along $69^{\circ} \mathrm{S}$ (near the southern edge of Larsen C) is $6.3 \mathrm{~mm}$ 

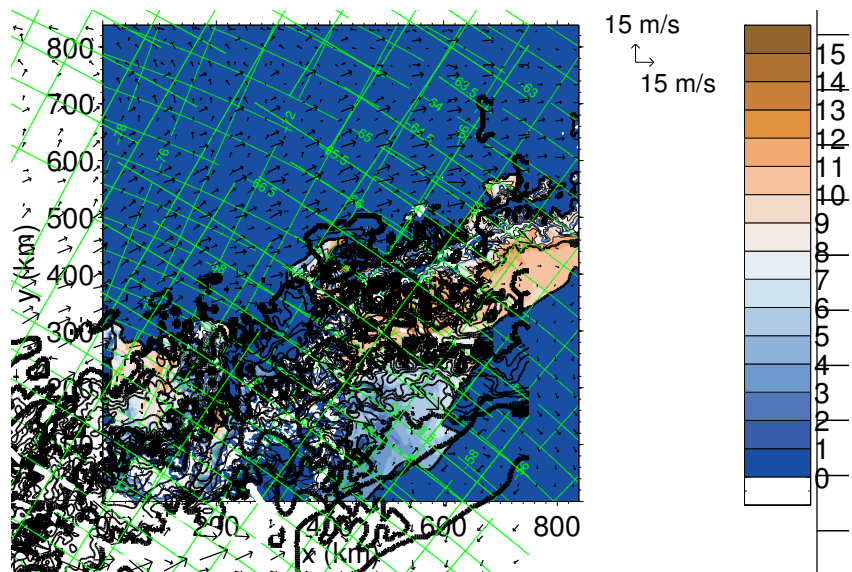

Figure 18. Total simulated snowmelt for domain 3 for the times of 12:00, 15:00, 18:00 and 21:00 UTC, 6 January in mm of water equivalent. The wind vectors are from the fourth model level taken at 12:00 UTC.

lower than at the reference point on Larsen B, a difference of $61 \%$. As for the melt line, the lines for $\mathrm{SW}_{\text {net }}$ and $\mathrm{LW}_{\text {net }}$ have also been shifted so that the values at $65.6^{\circ} \mathrm{S}$ latitude are zero. The other lines have not been shifted.

The individual components of the energy balance for melting at the ice surface are now examined.

\subsubsection{Short-wave radiation}

Figure 19 shows that $\mathrm{SW}_{\text {net }}$ provides by far the largest contribution to the melting throughout the simulation. At the reference point on Larsen B, for example, the energy it provides is 1.9 times that of the net melting energy. The dominant contribution of solar flux to the melting highlights the likely importance of factors that influence the amount of solar energy absorbed by the ground such as cloud cover and surface albedo. Very little cloud cover was produced over the ice shelf during the simulation, which is consistent with the aircraft observations and the satellite image shown in Fig. 7.

The change with latitude of the contribution of $\mathrm{SW}_{\text {net }}$ flux to melting is quite small. The $\mathrm{SW}_{\text {net }}$ contribution is only $0.9 \mathrm{~mm}$ less at $69^{\circ} \mathrm{S}$ compared to at the reference location, although this comprises $15 \%$ of the overall change in melting energy between the two locations. The modelled change is likely mainly caused by changes in the solar zenith angle since very little cloud was simulated.

\subsubsection{Long-wave radiation}

Heat losses from $L W_{\text {net }}$ represent the second largest term in the net melting balance at the Larsen B reference point, representing $93 \%$ of the net melting energy. Therefore, factors that affect the balance of LW (e.g. cloud cover; and the temperature and greenhouse gas concentrations of the air column above the ice shelf) are also likely to have a large impact on

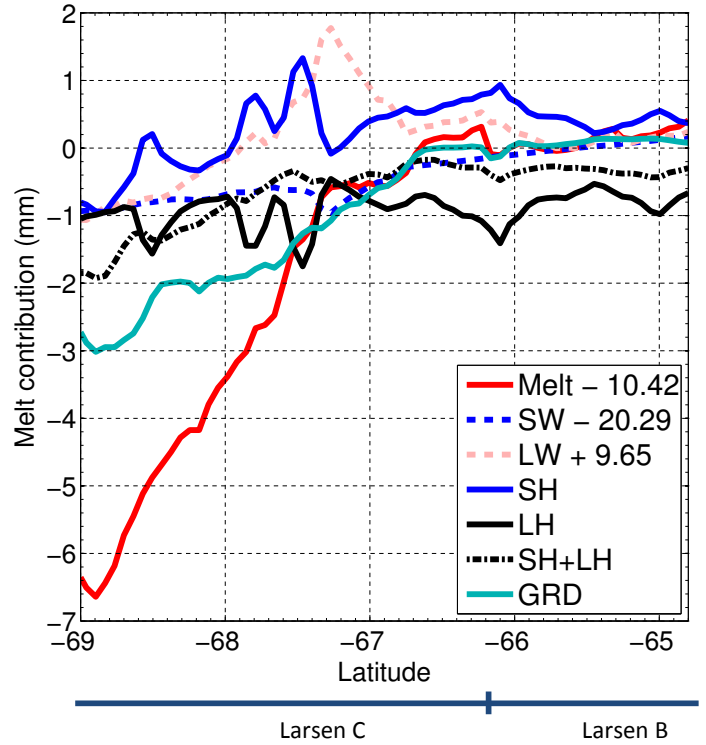

Figure 19. Simulated total melting amount averaged along lines of constant latitude across the Larsen ice shelf ("Melt") for the times of 12:00, 15:00, 18:00 and 21:00 UTC, 6 January. Also shown are the net contributions to the surface melting (i.e. positive values indicate a net downward contribution) at these times from short-wave radiation ("SW"), long-wave radiation ("LW"), sensible heat flux ("SH"), latent heat flux ("LH"), combined sensible and latent heat flux ("SH + LH") and ground heat flux ("GRD"). The lines "Melt", "SW" and "LW" have been shifted by $-19.8,-27.7$ and $+7.6 \mathrm{~mm}$ respectively in order to make all the lines visible on the same plot. These shifts were designed to make the values zero at the Larsen B reference location at $65.6^{\circ} \mathrm{S}$. The approximate boundary between Larsen B and Larsen C is also marked.

the melting of snow on the ice shelves. However, changes in cloud cover will have opposite effects on the downwelling short-wave and long-wave fluxes. Since the ice shelf surface temperature is fixed at $0^{\circ} \mathrm{C}$ during melting, the loss of energy due to upward LW emission will only be affected by the surface emissivity.

South of $67.9^{\circ} \mathrm{S}$ the LW loss is larger than at the reference location, but north of there, a region of reduced LW loss is present. The largest difference occurs at $67.3^{\circ} \mathrm{S}$ where there is $1.8 \mathrm{~mm}$ extra LW melt energy contribution compared to at the reference location. This region is close to the region of the föhn jets, suggesting that they are associated with increased downwelling LW. The difference in LW between Larsen B and the south of Larsen C $\left(69^{\circ} \mathrm{S}\right)$ is $1.1 \mathrm{~mm}$, which is similar to the change in the SW flux, but significantly less than the difference in both the combined sensible and latent heat fluxes $(\mathrm{SH}+\mathrm{LH})$, and the ground heat flux (described shortly). 


\subsubsection{Ground heat flux}

Very little heat is lost to the ground below the surface at the Larsen B reference point and there are in fact some slight gains in heat flux to the surface further north of there. This indicates that the ice below the surface at these latitudes is assumed by the model to be near to $0^{\circ} \mathrm{C}$, so that little heat energy is conducted away from the surface during melting. It may also be the case that for this location heat is gained during non-melting times when the surface is at sub-zero temperatures.

Loss of heat to the ground below the surface generally increases with distance south from the reference location. At $69^{\circ} \mathrm{S}$ ground heat loss represents $23 \%$ of the net melt energy. The result suggests that, whilst secondary to SW and LW, factors that affect the ground heat flux still have the potential to change melting rates by a significant amount at more southerly latitudes.

The difference in ground heat loss between the Larsen B ice shelf and the southern parts of the Larsen C ice shelf provides the largest contribution to the difference in melting rate between the two locations. For example, the ground heat flux difference between the Larsen B reference location and $69^{\circ} \mathrm{S}$ accounts for $42 \%$ of the difference in melting between the two locations. Thus, the change in ground heat flux with distance south over the ice shelf is the most important factor in determining the change in melting rates across the ice shelf, at least in this model.

Potential deficiencies in the model representation of ground heat fluxes are discussed in Sect. 5.

\subsubsection{Latent and sensible heat flux}

At the reference location on Larsen B the sensible heat flux contribution is $\sim 0.4 \mathrm{~mm}$. However, the positive contributions due to sensible heat flux are negated by a larger negative contribution of $-0.7 \mathrm{~mm}$ from latent heat flux. This represents the heat lost due to the direct ablation of ice. The negative contributions from the latent heat flux are larger than the positive ones from the sensible heat flux across the whole ice shelf region, so that their combined effect is always to decrease the melt energy.

There are a few positive spikes in the sensible heat flux term between 67.5 and $68.6^{\circ} \mathrm{S}$, which closely approximates the positions where the jets A, B and C (see Fig. 8a and Sect. 3.3) reach the foot of the Peninsula mountain on the ice shelf, indicating that they are the cause. Plots of the simulated sensible heat flux at times when the jets are present (not shown) reveal that the warm air of the jets leads to large positive sensible heat fluxes due to transfer of heat to the surface. However, as described above, this is offset by latent heat losses since, as well as being warm, the föhn air is very dry and so leads to extra snow ablation. The relatively small overall contribution from $\mathrm{SH}+\mathrm{LH}$ suggests that the jets do not significantly affect the energy available for melting through these processes. Note that in the recent study of Elvidge et al. (2014) the föhn air during a similar upwind blocking case was actually cooler than the surrounding air since it was associated with gap flow that had descended less than the larger scale flow. It would be interesting to compare these two cases in order to understand these differences, although this is beyond the scope of this study.

The trend of the $\mathrm{SH}+\mathrm{LH}$ flux is negative with distance south and is likely to be mainly driven by the changes in $\mathrm{SH}$ flux, which is most likely due to the increasing influence of cold air from the south. At $69^{\circ} \mathrm{S}$ the combination of sensible and latent heat flux contributes to $29 \%$ of the difference in melting energy between here and the reference location. Across most of Larsen C, it is the second largest term (behind the ground heat flux) in explaining the difference between the north and the south. It is possible that föhn jets may play some role in preventing cold air from the south from encroaching onto the ice shelf. In non-föhn conditions such encroachment might lead to larger SH losses than those simulated here.

\subsection{Discussion of the melting results in light of the previous literature}

Kuipers Munneke et al. (2012) examined surface energy balance data from two AWS on the ice shelf; one at $67^{\circ} \mathrm{S}$, $61.5^{\circ} \mathrm{W}$ and one at $67.6^{\circ} \mathrm{S}, 62.1^{\circ} \mathrm{W}$. They identified a melting event that was likely caused by föhn winds occurring between 10-18 November 2010 and contrasted it to the nonföhn period afterwards. Whilst the results were for a different time of year and different conditions to the event studied in this paper, a comparison provides some useful insight.

For example the daily mean melt amount for the period was $7.7 \mathrm{~mm}$ water equivalent (w.e.), which is similar to the daily melt from the WRF simulations presented here for the same latitude $(9.8 \mathrm{~mm})$. The melting rates from Kuipers Munneke et al. (2012) were, however, quite variable from day to day with the low melt days generally corresponding to low net SW input. Also, the melt due to $\mathrm{SH}$ and $\mathrm{LH}$ were generally quite large compared to the WRF simulation values, with mean values of 4.3 and $-3.4 \mathrm{~mm}$, respectively. The average WRF values for the melting period were, respectively, 0.5 and $-0.9 \mathrm{~mm}$. Despite different averaging periods and scales, the difference suggests that the model values are too low, which was also the conclusion from the comparison with the King et al. (2008) values.

A comparison of the non-föhn and föhn periods identified in Kuipers Munneke et al. (2012) showed that net surface SW input was higher in the föhn period (equivalent mean melt values of 16.3 vs. $9.8 \mathrm{~mm}$ ), as were net longwave losses $(-12.8$ vs. $-6.5 \mathrm{~mm})$. This is consistent with the idea of a lack of cloud during föhn events. There was also a large change in the sensible heat flux contribution (4.3 vs. $-1.8 \mathrm{~mm})$ but little change in latent heat flux $(-3.4 \mathrm{vs}$. $-2.9 \mathrm{~mm}$ ), suggesting that the energy provided by the warm 
air of a föhn event makes an important contribution to the melting flux given the mean melt during the föhn event of $7.7 \mathrm{~mm}$. The overall melting energy of the non-föhn period was only $0.2 \mathrm{~mm}$.

Holland et al. (2011) made estimates of the firn air content of the Larsen $\mathrm{C}$ ice shelf using aircraft-based radio echo sounding data from the austral summer of 1997-1998. Lower values of firn air content indicate that more melting has taken place in order to displace air that was contained within the ice. The relative decrease of air content with distance north along Larsen $\mathrm{C}$ gives some suggestion that more surface melting in the northern parts has taken place. The pattern of air content is strongly anti-correlated to the pattern of melting seen in Fig. 18, except for the region near the AP ridge between 67 and $68.5^{\circ} \mathrm{S}$. Tedesco (2009) provides estimates from satellite of the number of melt days per year; Holland et al. (2011) provides a closeup of this over the Larsen ice shelves. There is a strong similarity between Fig. 18 and these estimates. The strong similarity between the spatial pattern of melt calculated from our model simulation of a single föhn event with the climatological distribution of melt inferred by Tedesco (2009) and Holland et al. (2011) suggests that föhn events play a major role in determining the spatial pattern of melt over the Larsen ice shelf. The agreement of the model spatial pattern with those in Tedesco (2009) occurs even in the regions near the ridge, which was not the case for the Holland et al. (2011) firn air data. This suggests that other factors apart from melting might contribute to the differences in air content in those regions.

\section{Discussions and conclusions}

We have shown results from a WRF simulation of a föhn jet event that occurred during westerly flow over the Antarctic Peninsula (AP) mountain ridge. Aircraft profiles taken during the event in the north-eastern part of the Larsen $\mathrm{C}$ ice shelf showed jets over the Larsen $\mathrm{C}$ ice shelf with maximum wind speeds of $13-15 \mathrm{~m} \mathrm{~s}^{-1}$ at a height of $\sim 250-350 \mathrm{~m}$. At these heights the wind direction was southerly. The analysis showed that the meteorological situation consisted of a large low-pressure system centred $\sim 1250 \mathrm{~km}$ to the south-east of Larsen $\mathrm{C}$ and a high pressure region to the north and west of the AP. These systems were such that winds at the height of the ridge top were directed perpendicularly to the ridge line, which was likely an important factor in causing the föhn flows.

Profiles through the centres of the simulated jets showed a very good match to those observed by the aircraft for wind speed, wind direction and temperature suggesting that the model simulation was close to approximating the real jets. However, the good match only occurred at a model time corresponding to $\sim 9 \mathrm{~h}$ before the aircraft observations of the real jet were made. At the time of the observations, the jets in the model had died down to become much weaker than those observed. Thus, the model jets died down too early compared to reality. This could also help to explain why only model profiles taken considerably closer to the foot of the AP ridge than the aircraft observation location produced a good match; since the model jets died down too early they were likely too weak by the time they reached further east.

Near-surface data from an automatic weather station (AWS) located near the far north-east corner of Larsen C were also examined and showed that the observed and modelled wind direction showed a very similar evolution if the modelled time series was shifted forwards by $\sim 9 \mathrm{~h}$. The wind direction was characterised by a shift from a constant direction to a steady rotation around all directions of the compass over the course of $16 \mathrm{~h}$, which was traced to the shifting large-scale meteorological situation in the model. This makes problems with the analysis the most likely cause of the discrepancy between the model and the observations in terms of the early decay of the jet in the model and potentially also the weakness of the modelled jets in the eastern part of the ice shelf.

The good match between the modelled and real jets (except for the timing issues just mentioned) suggests that the modelled jets will give some insight into the locations and evolution of the real jets. The model resolved the wide jet that was present in the analysis into three smaller jets that emanated from locations at the foot of the AP between 67.4 and $68.6^{\circ} \mathrm{S}$. The two most northern jets merged as they travelled east, probably due to the influence of the Coriolis force, and missed the location of the aircraft observations. Coriolis turning also turned the third (southernmost) jet so that by the time it reached the observation location its wind direction was southerly in agreement with the measurements. This indicates that the observed jet likely emanated from near $68.6^{\circ} \mathrm{S}$ in a similar manner.

This work has implications for the determining the optimal positioning of AWSs if the goal is to observe föhn jets. The model wind fields suggest that there is some disconnect between the wind fields at the height of the maximum wind speeds and the near-surface winds. The near-surface winds were mainly influenced by the surface pressure field, which in turn will be determined by the meteorology, topography, etc., as well as the jets. Thus in some situations the pressure field is likely to be such that the jet winds are missed by the AWS. Placement of the AWS nearer to the AP ridge where the jets emanate would reduce the likelihood of this. Relative to at higher altitudes where the jet maximum winds occurred, there was little influence from Coriolis turning, most likely because the wind speeds were lower.

The fact that a jet was present in the ECMWF analysis suggests that it may be possible to use this to examine jet occurrence over long timescales. However, the fairly coarse resolution of the analysis used here $\left(0.5^{\circ} \times 0.5^{\circ}\right)$ could not resolve the details of the small-scale jets and it remains an open question whether it can accurately capture the formation and development of all jet events. The lack of resolution 
may also affect any feedbacks to the larger scale meteorology and the simulation of any ramifications of the jets on the surface energy balance. Higher-resolution analysis is available for more recent periods, which will help to address this issue.

The work here has shown that föhn jets are likely to have implications for the surface energy balance of the Larsen Ice C Shelf. The effect on surface melting of ice may be especially important since this may have implications for the stability of the Larsen C ice shelf. Whilst the simulation in this paper is only one case study, the good agreement with longterm melting estimates (Holland et al., 2011; Tedesco, 2009) give some confidence in the conclusions drawn.

Because the air is dry from adiabatic descent, föhn events are likely to be associated with reduced cloud cover. This will increase solar heating of the surface. The modelling results here showed that short-wave (SW) input dominated the melting budget leading to large melting rates, even though there was an increase in long-wave (LW) cooling associated with clearer skies. This result was consistent with aircraft observations of this event (King et al., 2008) and with analysis from AWS stations for a different föhn event (Kuipers Munneke et al., 2012). However, the comparison with the aircraft showed that the model albedo $(\alpha)$ and emissivity $(\epsilon)$ were likely inaccurate, which would lead to large biases in predicted melting if uncorrected. The results highlight the sensitivity of melting estimates to these parameters, which is due to the fact that melting flux is calculated from the difference between large terms. Thus it is important to obtain accurate $\alpha$ and $\epsilon$ values in both modelling and observational studies of surface melting.

There are also likely to be deficiencies in the model representation of short-wave absorption into the surface snow. Examples include the reduced albedo of melt pools; the trapping and internal reflection of radiation inside crevasses; general sub-surface absorption of short-wave radiation; and surface albedo changes due to snow property changes, aerosol deposition, etc.

Föhn jets are warm (near-surface air temperature $>0{ }^{\circ} \mathrm{C}$ ) and so caused an increase in the amount of downward sensible heat flux at the surface. However, because the jet air is also dry, surface energy loss due to snow ablation (latent heat fluxes) tends to cancel out a lot of the surface heating effect due to sensible heating. This was the case in the modelling in this study and this is also consistent with the aircraft observations and AWS analysis mentioned above. However, the comparison to those results suggests that the sensible and latent heat fluxes were underestimated in the model, indicating deficiencies in the model representation of these processes and their link to the jets, or of the föhn jets themselves. This is likely to implicate the surface layer scheme parameterisation. The selection of the Janjić Eta scheme (see Section 2.2 for details) used in this study was based upon the thorough testing of the various available WRF schemes in order to determine those that best matched observations over ice covered surfaces, as detailed in Hines and Bromwich (2008). However, improved accuracy could likely be obtained through the use of roughness length values and scalings that are tailored to the Larsen $\mathrm{C}$ ice shelf.

Simulated melting rates were significantly higher in the northern parts of the ice shelf than further south. The northern parts of Larsen $\mathrm{C}$ had similar melt rates to Larsen B, where the ice shelf collapsed in 2002. If melting was one of the major causes of the break-up as suggested (Scambos et al., 2000, 2004; van den Broeke, 2005) then this hints at the potential for ice shelf collapse in the northern parts of Larsen $\mathrm{C}$, if it can be assumed that the ice shelf structures are sufficiently similar. Differences in the energy budget as a function of latitude were examined in order to try and understand the predicted changes in melting rates across the ice shelf. It was found that the change of ground heat flux represented the largest change from the north to the south, despite the overall much larger contributions from SW and LW to the melting rate at a given location. Thus, this may be an important quantity to study and yet it cannot be easily measured from aircraft.

Whilst the model treatment of the thermal properties of the sub-surface snowpack were specially modified to deal with deep snowpack, including the use of density, heat capacity and heat conductivity values taken from observations of Antarctic snow firn (Hines and Bromwich, 2008), it is likely that some deficiencies still remain. The values provided within the WRF domain set-up utility were used for the initialisation of the sub-surface snow temperatures, which are based on annual averages. This therefore may introduce some errors in the ground heat flux and melting calculations since the use of seasonally varying sub-surface temperatures tailored for the Larsen $\mathrm{C}$ ice shelf would be more appropriate. Also, there may be some spin-up period for the temperatures of the sub-surface layers associated with the use of this data. Therefore, it is recommended that sub-surface temperature data from longer-term runs (i.e. with fully spun up sub-surface temperatures) of this region are used for future studies (e.g. data from the Antarctic Mesoscale Prediction System, known as AMPS, or other polar WRF runs). The provision of sub-surface melt layers may also lead to better model accuracy in melting estimates.

The next largest contributor to the difference between northern and southern locations was the combination of sensible and latent heat flux due to the influence of cold air from the continent in the southern regions in contrast to the warmer föhn air further north. The frequency, strength and positions of föhn events are therefore likely to be important in determining melting rates in the south since this may determine whether the cold continental air is displaced or not. Changes in SW and LW were generally quite small from north to south.

Climate change is likely to affect the magnitudes and balance of these processes. Research has suggested that föhn frequency has increased over the past 50 years (Marshall 
et al., 2006) and this may continue to be the case in the future, which therefore might be expected to lead to more melt days over the Larsen ice shelves. Climate change may also affect the nature as well as the frequency of föhns. For example, warmer föhn flows and higher greenhouse gas concentrations would be expected to lead to lower net LW losses from the surface; LW surface loss was the second largest term in the melt energy budget at all locations. More föhn flows and general warmer temperatures might also cause the snowpack below the surface to reach higher temperatures due to heat transfer from the surface, thus leading to an overall reduction in ground heat flux losses. Since ground heat flux differences were found to be the main cause of the difference in melt energy between Larsen B and the south of Larsen C, it is feasible that this could play a role in increasing melt rates in the south towards the present-day rates in the north.

Overall, the results here suggest that föhn events are likely to be important in causing melting of the surface of the Larsen ice shelves and that increasing frequencies of föhn events will lead to increased surface melting. It is therefore important to assess what the overall climatological impact of föhn events is on surface melting of the Larsen ice shelves. The "cloud clearing" effect of föhn events, which is probably the most important factor for surface melting, might be detected using satellites and so this might represent one way to monitor föhn frequencies, barring obscuration from higher altitude clouds. Although, it may not be the case that all clear events are caused by föhn cases suggesting that some other measurement would also be required to determine whether a föhn event was taking place or not. As well as föhn frequency, the cloud fraction and thickness over the ice shelves on non-föhn days will also determine how much difference föhn events make to the overall melting budget. This is something else that might be studied using satellites, although there are known difficulties in performing passive satellite retrievals over ice surfaces that may need to be overcome. It would also be useful to determine whether surface melting can occur in cloudy conditions or in non-föhn clear-sky conditions.
Recent modelling work (Elvidge et al., 2014) presented simulations of a föhn case during upwind blocking with some similarities to the case presented here. However, there appear to be some key differences since the föhn jets were cooler than the surrounding air, which is the opposite to what was observed here. Understanding these differences would provide some interesting insight into these processes, but is unfortunately beyond the scope of our study. Finally, the likelihood from the results of this paper and from Elvidge et al. (2014) that föhn events can occur in conditions of strong upwind blocking has ramifications for how meteorological data is interpreted in terms of Larsen ice shelf surface melting. Our results suggest that reduced upwind blocking, due to wind speed increases or stability decreases, might not result in an increased likelihood of föhn events over the Antarctic Peninsula, as suggested in previous studies. Thus, increased westerly wind strength due to climate change may not necessarily correlate with föhn frequency. Rather, the results here suggest that the wind direction may be the most important factor, with föhn events perhaps being possible within a few different upwind stability regimes as long as the wind is perpendicular to the ridge. 


\section{Appendix A: L-shaped aircraft legs}

As well as making ascent and descent profiles the aircraft made a series of "L"-shaped flight legs at approximately constant altitude above the ice shelf surface. The L-shape of the flight path is indicated in Fig. 8d by the letters A, L1 and L2 at the far east side of the ice shelf. The first section, A-L1L2 was flown at $\sim 15.2 \mathrm{~m}$ above the surface at 20:23 UTC. Then this section was flown in reverse at $\sim 152 \mathrm{~m}$ starting at 20:48 UTC. A-L1-L2 was again flown at $305 \mathrm{~m}$ starting at 21:13 UTC followed by a final L2-L1-A leg at $610 \mathrm{~m}$, which started at 21:36 UTC.

Figure A1 shows the wind speeds and Fig. A2 the temperature during the L-shaped legs for the runs at the different heights plotted as a function of latitude for the A-L1 leg and longitude for the L1-L2 leg since the former is orientated almost east-west and the latter north-south. The legs at $305 \mathrm{~m}$ are very close in altitude to the height at which the maximum wind speeds were observed throughout the aircraft and model profiles $(=250 \mathrm{~m})$. The observed wind speed at the start of this leg (location A, 21:13 UTC) was $~ 13-$ $13.5 \mathrm{~m} \mathrm{~s}^{-1}$, which is close to that observed at this height during the earlier descent profile at $\sim 20: 23$ UTC. This indicates that the jet strength and position had not changed much during this time. The wind speed at this height generally decreased from just over 14 to $8 \mathrm{~m} \mathrm{~s}^{-1}$ as the aircraft moved north from A to L1 through to L2.

This fits with the orientation of the modelled wind jets at 15:00 UTC as in Fig. 8c: at this time the simulated jet 3 has rotated to be pointing in a north-south direction located just to the west of the area of the L-shaped legs, so that the wind speed is reducing with distance northwards. The observed wind direction (not shown) for this height throughout the L-shaped flight was fairly constant at $180-200^{\circ}$ and therefore was approximately from the south, which is again consistent with the simulated jet. The fairly strong winds observed by the aircraft at a height of $\sim 305 \mathrm{~m}$ throughout the L-shaped flight leg and the fairly constant warm temperatures of around $4-4.5^{\circ} \mathrm{C}$ (Fig. A2a) indicate that the spatial extent of the jet at least covered the region bounded by locations A, L1 and L2. The modelled jet at 15:00 UTC does not cover the A-L1-L2 region, but its centre is only $24 \mathrm{~km}$ west of the A-L1 line at location E (Fig. 8c).
During the legs at heights of $610 \mathrm{~m}$ and $152 \mathrm{~m}$ the wind speeds changed roughly consistently with the $305 \mathrm{~m}$ leg, although with different mean wind speeds (Fig. A1). The wind direction for these legs were also quite similar to that of the $305 \mathrm{~m}$ leg, i.e. from the south to south-west, and showed little variation (not shown). However, the observed properties at $15 \mathrm{~m}$ showed more variation. The wind direction generally changed from westerly to almost southerly from A to L2. The wind speed varied between 3 and $7 \mathrm{~m} \mathrm{~s}^{-1}$ and was close to that during the descent profile at A. There is an area of low wind speed near the point $\mathrm{L} 1$ where the temperatures are around $0.5^{\circ} \mathrm{C}$, which is considerably lower than elsewhere during the flight legs; there is another area of correlated lower wind speeds and temperatures close to $61.9^{\circ} \mathrm{W}$. This suggests that the warmer temperatures are not as widespread at lower levels than above and that the warm air of the jet winds might be less able to penetrate certain areas of the ice shelf near the surface. The winds at this height are not well correlated with the winds at the other heights, suggesting that different processes are acting at the different heights and that the low-level winds do not simply follow those at the height of the maximum jet wind speed. This is discussed in Sect. 3.5. 

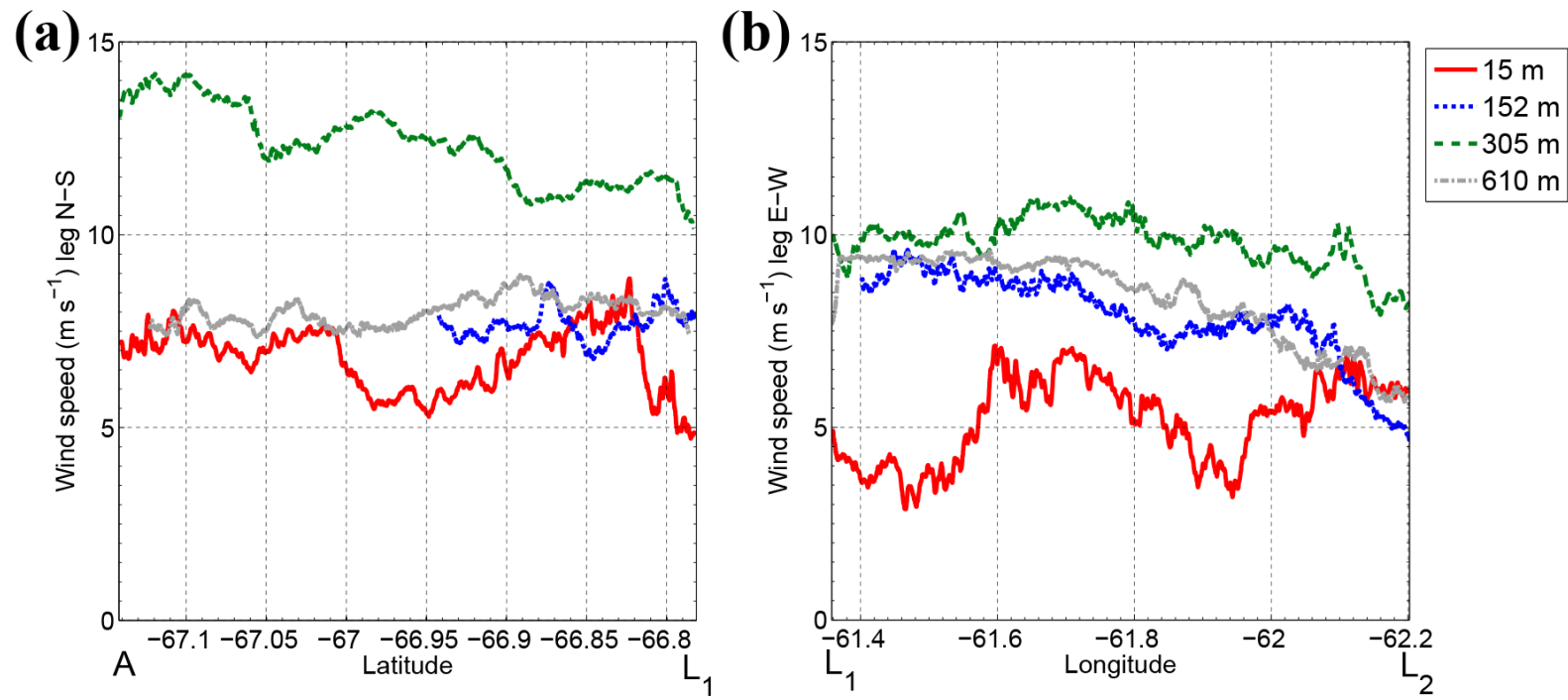

Figure A1. Wind speed during the "L" shaped legs flown from A to L1 to L2 at the heights indicated. See Fig. 8d for the position of these locations. The A-L1 leg was orientated close to south-north and the L1-L2 leg close to east-west. Thus, the $x$ axis was chosen to be latitude for the A-L1 leg (a) and longitude for the L1-L2 leg (b). Also, here the data has been smoothed over $3 \mathrm{~s}$ windows for clarity. Note, part of the N-S leg at $152 \mathrm{~m}$ in (a) has been removed due to wind measurement problems caused by a loss of GPS lock.
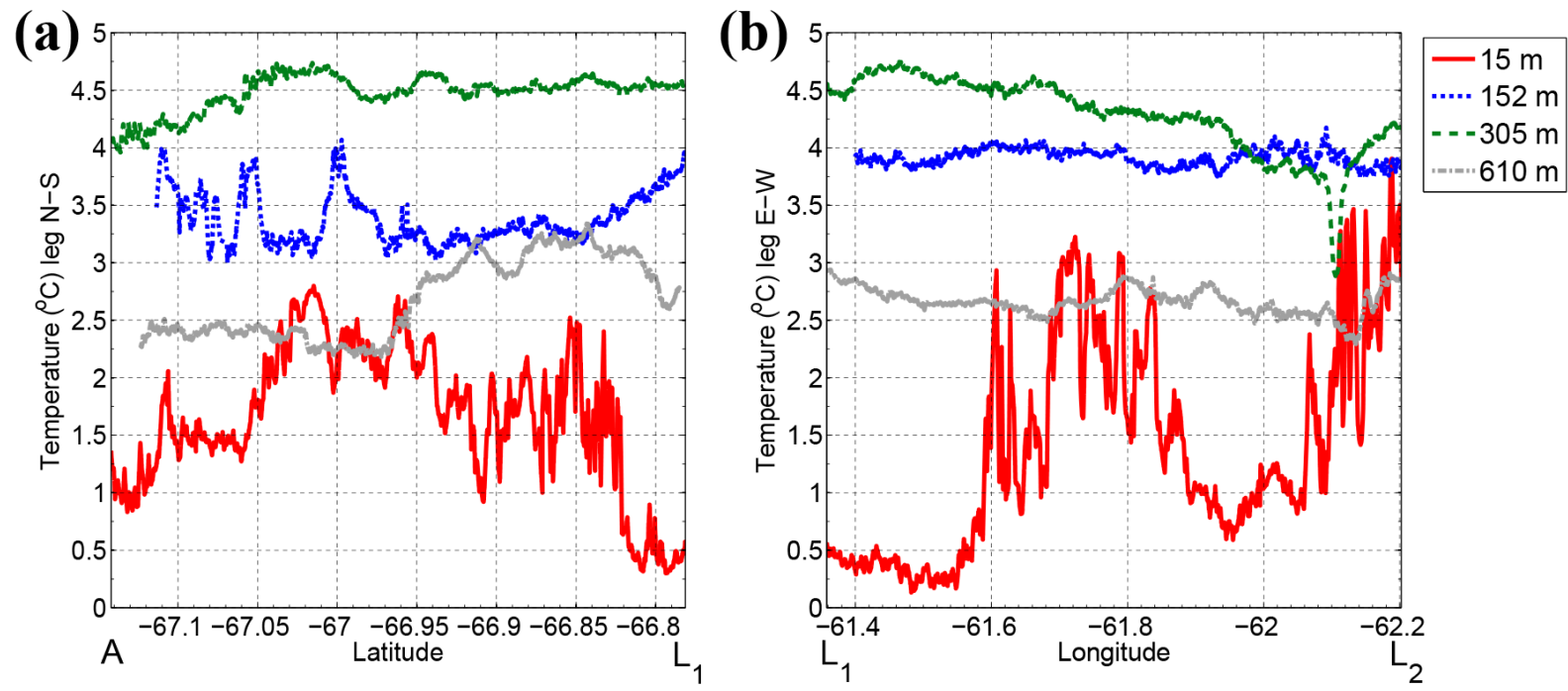

Figure A2. As for Fig. A1 except for temperature and with no smoothing. 
Acknowledgements. J. C. King and T. Lachlan-Cope acknowledge support from the UK Natural Environment Research Council under grant no. NE/G014124/1 "Orographic Flows and the Climate of the Antarctic Peninsula (OFCAP)". We also acknowledge ECMWF for access to archived analysis data and DPG acknowledges British Antarctic Survey (BAS) BCF support. We are also very thankful to Russ Ladkin for aircraft support. We very much appreciate the time taken by the anonymous referees and the editor in providing feedback that improved the paper.

Edited by: H. Wernli

\section{References}

Bromwich, D. H., Hines, K. M., and Bai, L.-S.: Development and testing of polar weather research and forecasting model: 2. Arctic Ocean, J. Geophys. Res.-Atmos., 114, D08122, doi:10.1029/2008JD010300, 2009.

Cai, W., Whetton, P., and Karoly, D.: The response of the Antarctic Oscillation to increasing and stabilized atmospheric $\mathrm{CO}_{2}$, J. Climate, 16, 1525-1538, doi:10.1175/1520-0442-16.10.1525, 2003.

Durran, D.: Another look at downslope windstorms .1. The development of analogs to supercritical-flow in an infinitely deep, continuously stratified fluid, J. Atmos. Sci., 43, 2527-2543, doi:10.1175/1520-0469(1986)043<2527:Aladwp>2.0.CO;2, 1986.

Durran, D.: Mountain waves and downslope flows, Atmospheric Processes over Complex Terrain, Meteor. Monographs, edited by: Blumen, W., Amer. Meteor. Soc., Boston, 59-81, 1990.

Durran, D. and Klemp, J.: Another look at downslope winds .2. Nonlinear amplification beneath wave-overturning layers, J. Atmos. Sci., 44, 3402-3412, doi:10.1175/15200469(1987)044<3402:Aladwp>2.0.CO;2, 1987.

Elvidge, A. D., Renfrew, I. A., King, J. C., Orr, A., LachlanCope, T. A., Weeks, M., and Gray, S. L.: Foehn jets over the Larsen C Ice Shelf, Antarctica, Q. J. Roy. Meteorol. Soc., doi:10.1002/qj.2382, 2014.

Gillett, N. and Thompson, D.: Simulation of recent Southern Hemisphere climate change, Science, 302, 273-275, doi:10.1126/science.1087440, 2003.

Hines, K. M. and Bromwich, D. H.: Development and testing of Polar Weather Research and Forecasting (WRF) model, Part I: Greenland ice sheet meteorology, Mon. Weather Rev., 136, 1971-1989, doi:10.1175/2007MWR2112.1, 2008.

Hines, K. M., Bromwich, D. H., Bai, L., Barlage, M., and Slater, A. G.: Development and Testing of Polar WRF. Part III: Arctic Land, J. Climate, 24, 26-48, doi:10.1175/2010JCLI3460.1, 2011.

Holland, P. R., Corr, H. F. J., Pritchard, H. D., Vaughan, D. G., Arthern, R. J., Jenkins, A., and Tedesco, M.: The air content of Larsen Ice Shelf, Geophys. Res. Lett., 38, L10503, doi:10.1029/2011GL047245, 2011.

Houghton, D. and Kasahara, A.: Nonlinear shallow fluid flow over an isolated ridge, Commun. Pur. Appl. Math., 21, 1-23, doi:10.1002/Cpa.3160210103, 1968.

Hunt, J. and Snyder, W.: Experiments on stably and neutrally stratified flow over a model 3-dimensional hill, J. Fluid Mech., 96, 671-704, doi:10.1017/S0022112080002303, 1980.
Janjić, Z., I.: Nonsingular implementation of the Mellor-Yamada level 2.5 scheme in the NCEP Eta Model, NCEP Office Note 437, 61 pp., http://www.lib.ncep.noaa.gov/ncepofficenotes/files/ on437.pdf (last access: 3 September 2014), 2002.

King, J. C. and Turner, J.: Antarctic Meteorology and Climatology, Cambridge University Press, Cambridge, 83-84, 1997.

King, J. C., Lachlan-Cope, T. A., Ladkin, R. S., and Weiss, A.: Airborne measurements in the stable boundary layer over the Larsen Ice Shelf, Antarctica, Bound.-Lay. Meteorol., 127, 413428, doi:10.1007/s10546-008-9271-4, 2008.

Kuipers Munneke, P., van den Broeke, M. R., King, J. C., Gray, T., and Reijmer, C. H.: Near-surface climate and surface energy budget of Larsen C ice shelf, Antarctic Peninsula, The Cryosphere, 6, 353-363, doi:10.5194/tc-6-353-2012, 2012.

Kushner, P., Held, I., and Delworth, T.: Southern Hemisphere atmospheric circulation response to global warming, J. Climate, 14, 2238-2249, doi:10.1175/15200442(2001)014<0001:SHACRT>2.0.CO;2, 2001.

Marshall, G. J., Orr, A., van Lipzig, N. P. M., and King, J. C.: The impact of a changing Southern Hemisphere annular mode on Antarctic Peninsula summer temperatures, J. Climate, 19, 53885404, doi:10.1175/JCLI3844.1, 2006.

Miglietta, M. M. and Buzzi, A: A numerical study of moist stratified flows over isolated topography, Tellus A, 53, 481-499, doi:10.1111/j.1600-0870.2001.00481.x, 2001.

Miles, J. and Huppert, H.: Lee waves in a stratified flow .4. Perturbation approximations, J. Fluid Mech., 35, 497-525, doi:10.1017/S0022112069001248, 1969.

Orr, A., Cresswell, D., Marshall, G., Hunt, J., Sommeria, J., Wang, C., and Light, M.: A "low-level" explanation for the recent large warming trend over the western Antarctic Peninsula involving blocked winds and changes in zonal circulation, Geophys. Res. Lett., 31, L06204, doi:10.1029/2003GL019160, 2004.

Orr, A., Marshall, G. J., Hunt, J. C. R., Sommeria, J., Wang, C.-G., van Lipzig, N. P. M., Cresswell, D., and King, J. C.: Characteristics of summer airflow over the Antarctic Peninsula in response to recent strengthening of westerly circumpolar winds, J. Atmos. Sci., 65, 1396-1413, doi:10.1175/2007JAS2498.1, 2008.

Peltier, W. and Clark, T.: Evolution and stability of finite-amplitude mountain waves .2. Surface-wave drag and severe downslope windstorms, J. Atmos. Sci., 36, 1498-1529, doi:10.1175/15200469(1979)036<1498:Teasof>2.0.CO;2, 1979.

Scambos, T., Hulbe, C., Fahnestock, M., and Bohlander, J.: The link between climate warming and break-up of ice shelves in the Antarctic Peninsula, J. Glaciol., 46, 516-530, doi:10.3189/172756500781833043, 2000.

Scambos, T., Bohlander, J., Shuman, C., and Skvarca, P.: Glacier acceleration and thinning after ice shelf collapse in the Larsen B embayment, Antarctica, Geophys. Res. Lett., 31, L18402, doi:10.1029/2004GL020670, 2004.

Skamarock, W. C. and Klemp, J. B.: A time-split nonhydrostatic atmospheric model for weather research and forecasting applications, J. Comput. Phys., 227, 3465-3485, doi:10.1016/j.jcp.2007.01.037, 2008.

Smith, R.: On severe downslope winds, J. Atmos. Sci., 42, 25972603, doi:10.1175/1520-0469(1985)042<2597:Osdw>2.0.CO;2, 1985.

Smith, R.: Hydrostatic air-flow over mountains, Adv. Geophys., 31, 1-41, doi:10.1016/S0065-2687(08)60052-7, 1989. 
Smith, R. and Sun, J. L.: Generalized Hydraulic Solutions Pertaining To Severe Downslope Winds, J. Atmos. Sci., 44, 2934-2939, doi:10.1175/1520-0469(1987)044<2934:Ghspts>2.0.CO;2, 1987.

Steig, E. J., Schneider, D. P., Rutherford, S. D., Mann, M. E., Comiso, J. C., and Shindell, D. T.: Warming of the Antarctic ice-sheet surface since the 1957 International Geophysical Year, Nature, 457, 459-462, doi:10.1038/nature07669, 2009.

Tedesco, M.: Assessment and development of snowmelt retrieval algorithms over Antarctica from K-band spaceborne brightness temperature (1979-2008), Remote Sens. Environ., 113, 979_ 997, doi:10.1016/j.rse.2009.01.009, 2009.

Thompson, D. and Solomon, S.: Interpretation of recent Southern Hemisphere climate change, Science, 296, 895-899, doi:10.1126/science.1069270, 2002.

Turner, J., Colwell, S., Marshall, G., Lachlan-Cope, T., Carleton, A., Jones, P., Lagun, V., Reid, P., and Iagovkina, S.: Antarctic climate change during the last 50 years, Int. J. Climatol., 25, 279-294, doi:10.1002/joc.1130, 2005.

van den Broeke, M.: Strong surface melting preceded collapse of Antarctic Peninsula ice shelf, Geophys. Res. Lett., 32, L12815, doi:10.1029/2005GL023247, 2005. van Lipzig, N. P. M., Marshall, G. J., Orr, A., and King, J. C.: The relationship between the Southern Hemisphere annular mode and Antarctic Peninsula summer temperatures: analysis of a high-resolution model climatology, J. Climate, 21, 1649-1668, doi:10.1175/2007JCLI1695.1, 2008.

Vaughan, D., Marshall, G., Connolley, W., Parkinson, C., Mulvaney, R., Hodgson, D., King, J., Pudsey, C., and Turner, J.: Recent rapid regional climate warming on the Antarctic Peninsula, Climatic Change, 60, 243-274, doi:10.1023/A:1026021217991, 2003.

Wilson, A. B. and Bromwich, D. H., and Hines, K. M.: Evaluation of Polar WRF forecasts on the Arctic System Reanalysis domain: Surface and upper air analysis, J. Geophys. Res.-Atmos., 116, D11112, doi:10.1029/2010JD015013, 2011.

Zilitinkevich, S.: Non-local turbulent transport: Pollution dispersion aspects of coherent structure of convective flows, Air Pollution III, Vol 1: Air Pollution Theory and Simulation, 5360, edited by: Power, H., Moussiopoulos, N., and Brebbia, C. A., 3rd International Conference on Air Pollution (Air Pollution 95), Porto Carras, Greece, 26-29 September 1995, Wessex Inst Technol, Southampton; Aristotle Univ Thessaloniki, Sch Engn, Greece, Compuational Mechanics Publications Ltd., Ashurst Lodge, Southampton, Hants, England SO4 2AA, 1995. 